NASA Technical Memorandum 102344

ICOMP-89-22

\title{
A New Uniformly Valid Asymptotic Integration Algorithm for Elasto-Plastic- Creep and Unified Viscoplastic Theories Including Continuum Damage
}

A. Chulya

Institute for Computational Mechanics in Propulsion

Lewis Research Center

Cleveland, Ohio

and

K.P. Walker

Engineering Science Software, Inc.

Smithfield, Rhode Island

December 1989 


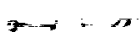

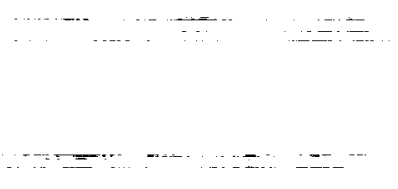

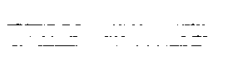

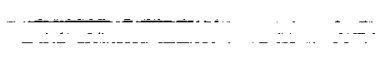

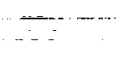

$(-1+\cdots$

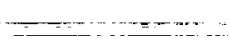

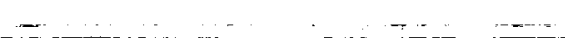




\title{
A NEW UNIFORMLY VALID ASYMPTOTIC INTEGRATION ALGORITHM
}

FOR ELASTO-PLASTIC-CREEP AND UNIFIED VISCOPLASTIC

\section{THEORIES INCLUDING CONTINUUM DAMAGE}

\author{
A. Chulya \\ Institute for Computational Mechanics in Propulsion \\ NASA Lewis Research Center \\ Cleveland, Ohio \\ and \\ K.P. Wa 1 ker \\ Engineering Science Software, Inc. \\ Smithfield, Rhode Island
}

\section{ABSTRACT}

A new scheme to integrate a system of stiff differential equations for both the elasto-plastic-creep and the unified viscoplastic theories is

presented. The method has high stability, allows large time increments, and is implicit and iterative. It is suitable for use with continuum damage theories. The scheme was incorporated into MARC, a commercial finite element code through a user subroutine called HYPELA. Results from numerical problems under complex loading historles are presented for both small and large scale analysis. To demonstrate the scheme's accuracy and efficiency, comparisons to a self-adaptive forward Euler method are made.

\section{NOMENCLATURE}

[B] strain-displacement transformation matrix

[C] stress-strain material property matrix

E Young's modulus

$e_{i j}$ deviatoric strain tensor

$e_{i j}^{p}$ deviatoric plastic strain tensor

$e^{-C} \quad$ effective creep strain

$e^{-p} \quad$ effective plastic strain 


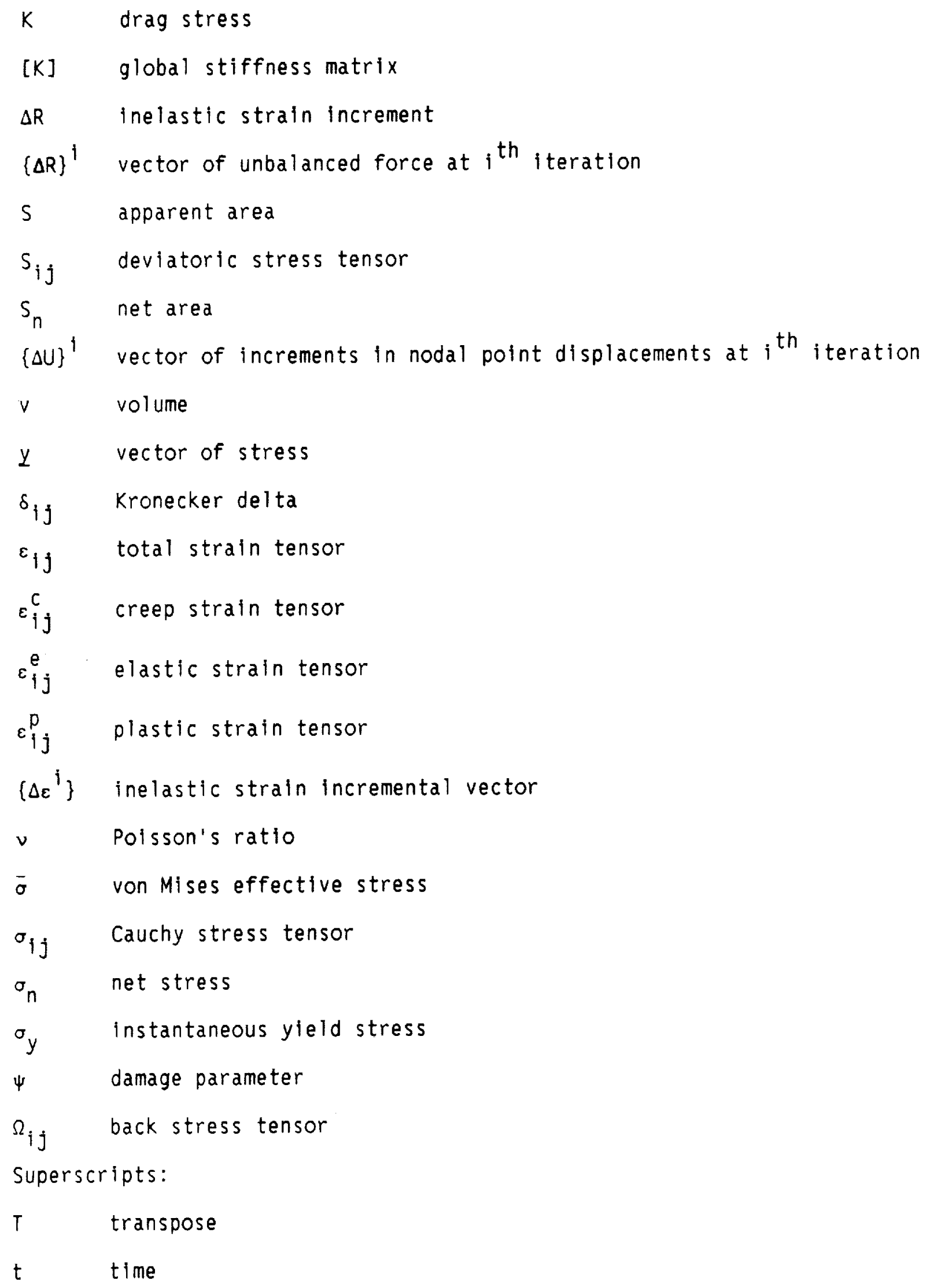


- initial value

- rate

INTRODUCTION

The increasing demand for integrity and reliability in metallic structural components that have been subjected to a complex cyclic thermomechanical environment has stimulated the improvement of inelastic analys is methodology. The aerospace industry very much needs durable and efficient combustor and turbine structural components in the modern gas turbine engine. Creep and fatigue cracking and creep buckling distortion of combustor liners caused by high temperatures and impact and erosion damage decrease turbine durability; this has led to the development of a phenomenological theory of unified constitutive equations that describe time and temperature dependence in the plastic regime, in contrast to the time-independence of classical plasticity. In the past the inelastic strain comprised a time-independent (plasticity) and a time-dependent (creep) term; these terms were calculated by using classical plasticity and creep theories, respectively. However the physical interaction between creep and plasticity was observed through several deformation phenomena, that is, cyclic hardening or softening, creep recovery, and rate sensitivity. The unified constitutive theory is considered to be superior in predicting and governing the physical process, as compared to the classical plasticity-creep theory.

Although neither theory has been widely applied in structural analysis of samples under complex loading histories, the unified constitutive theory has been especially neglected. This is due mainly to difficulties associated with the system of very stiff differential equations in certain regimes. This mathematical stiffness requires use of a very small time step in order to integrate the constitutve models without loss of stability. As a result, 
computation time becomes enormous, and under complex loading, solving the problems often becomes impossible.

The importance of an efficient alogirthm to integrate the inelastic constitutive models is obvious. An explicit algorithm, such as a forward Euler in conjunction with a self-adaptive scheme, has been widely used largely because it is simple and the computation is inexpensive. However, this algorithm is a subincremental type, which is noniterative in nature. In this case, convergence of the solutions depends significantly on the judgment of engineers, who tend to be conservative. An implicit alogorithm, which is an iterative type, is more stable amd accurate but prohibitively expensive. In recent years, several approaches have been developed to make the algorithm less dependent on the analysts. Banthia and Mukherjee (1982), with their one-step Euler integration scheme with a variable time step, improved the scheme by imposing a better time-step control. This approach takes advantage of the fact that the equations appear to be stiffer for large strain rates. They chose a time step that gives more accurate results, but it is slightly less efficient than their previous algorithm. Miller and Tanaka (1988) developed a noniterative, self-correcting solution (NONSS). Their method is similar to the Newmark $\beta$-method in that a parameter that determines whether the method is explicit or implicit is introduced. This method reduces to the forward Euler method when $\beta>0$. Implicit quantities are removed in the NONSS method by Taylor expansions of state variables. The NONSS method is unconditionally stable of $\beta \geq 1 / 2$, but it requires setting up a Jacobian matrix and solving a set of linear equations at each time step. Accuracy is maintained through self-adaptive time control and by correcting errors at the current step. Since this method has been used in one-element applications only, its applicability to finite element analysis remains to be seen. 
Despite these efforts, a generally applicable method that is implicit, iterative, stable, and inexpensive as well as convenient for implementation into finite element codes has not yet been developed. The objective of this report is to demonstrate such a method. The proposed method is based on transforming the differential equations of constitutive models to an integrated form as proposed by Walker $(1976,1980)$. These integrated equations are then approximated by uniformly valid asymptotic expansions (UVAE). A concise mathematical derivation is presented for both the classical theory of plasticity and creep and the unified viscoplastic theory. The advantage of this method in continuum damage mechanics is presented as we 11 . Implementation into the commercial MARC finite element code is demonstrated. Results of numerical examples for small-and large-scale problems at high temperatures are then presented. Comparisons to the self-adaptive forward Euler (SAFE) scheme are made as well, to show the accuracy and efficiency of the proposed integration scheme.

DIFFERENTIAL FORMS OF ELASTO-PLASTIC-CREEP AND UNIFIED VISCOPLASTIC CONSTITUTIVE EQUATIONS

A fundamental observation when comparing elastic and inelastic analysis is that for elastic solutions the total stress can be determined from the total strain alone, whereas in an inelastic response calculation the total stress beyond the yield point depends on both the stress and strain histories. Typical inelastic phenomena are plasticity, creep, and viscoplasticity, and a very large number of material models have been developed in order to characterize such material response. In this section the basic forms of differential equations for both the classical theory of plasticity and creep 
and the unified viscoplastic theory are presented. A brief review of the wellknown, self-adaptive forward Euler (SAFE) integration algorithm is included in the last part of this section.

Classical Theory of Creep and Plasticity

The simplest and most widely used material model by far employs the classical plasticity theory to characterize short-term deformation and the classical creep theory to characterize long-term deformation. The differential equations are formulated explicitly and independently. For small displacement and small strain formulation, the total strain rate $\dot{\varepsilon}_{i j}$ is decomposed into elastic, plastic, and creep strain rates,

$$
\dot{\varepsilon}_{i j}=\dot{\varepsilon}_{i j}^{e}+\dot{\varepsilon}_{i j}^{p}+\dot{\varepsilon}_{i j}^{c}
$$

where $\dot{\varepsilon}_{i j}=$ component of total strain rate tensor, $\dot{\varepsilon}_{i j}=$ component of elastic strain rate tensor, $\dot{\varepsilon}_{i j}^{p}=$ component of plastic strain rate tensor, $\dot{\varepsilon}_{i j}^{c}=$ component of creep strain rate tensor. The constitutive law for an isotropic material with temperature-dependent moduli (Fung, 1965; Malvern, 1969) is

$$
\dot{\sigma}_{i j}=c_{i j r s}\left(\dot{\varepsilon}_{r s}-\dot{\varepsilon}_{r s}^{p}-\dot{\varepsilon}_{r s}^{c}\right)
$$

where

$$
C_{i j r s}=\lambda \delta_{i j} \delta_{r s}+\mu\left(\delta_{i r} \delta_{j s}+\delta_{i s} \delta_{j r}\right)
$$

$\lambda=E v /(1+v)(1-2 v) ; \mu=E / 2(1+v) ; E=$ Young's modulus; $\nu=$ Poisson's ratio; and $\delta_{i j}=$ Kronecker delta.

The plastic strain rate is calculated by using the classical theory of time-independent plasticity (Meldelson, 1968; Fung, 1965; Malvern, 1969). The von Mises yield function for nonisothermal, isotroplc haradening can be written as 


$$
F=\frac{1}{2} S_{i j} S_{i j}-\frac{1}{3} \sigma_{y}^{2}
$$

where $\sigma_{y}$ is the instantaneous yield stress and $S_{i j}$ is the deviatoric stress tensor defined as $S_{i j}=\sigma_{i j}-\left(\delta_{i j} \sigma_{k k} / 3\right)$. The plastic strain rate is defined as

$$
\dot{\varepsilon}_{i j}^{p}=\Psi S_{i j}
$$

where $\Psi$ is a positive scalar variable defined as

$$
\Psi=\frac{3}{2 \sigma_{y}}\left(\frac{\partial \overline{\mathrm{e}}^{\mathrm{p}}}{\partial \sigma_{y}} \dot{\sigma}_{y}+\frac{\partial \overline{\mathrm{e}}^{\mathrm{p}}}{\partial \theta} \dot{\theta}\right)
$$

$e^{-p}$ is effective plastic strain,

$$
\vec{e}^{p}=\left(\frac{2}{3} e_{i j}^{p} e_{i j}^{p}\right)^{1 / 2}
$$

$e_{i j}^{p}$ is deviatoric plastic strain, and $\theta$ is the temperature. With the yield stress defined as a function of the effective plastic strain ēp and temperature $\theta$, Eq. (6) can be used directly to evaluate $\Psi$ (Snyder, Bathe, 1981).

The creep strain rate is determined by using a modified equation-of-state approach. This approach includes strain hardening for variable loading and the Oak Ridge National Laboratory's auxiliary hardening rules of cyclic behavior (Pugh et al., 1972). The final result is written as

$$
\dot{\varepsilon}_{i j}^{c}=\Gamma S_{i j}
$$

where $\Gamma$ is a scalar variable,

$$
\Gamma=\frac{3 e^{-} c}{2 \bar{\sigma}}
$$

$\bar{\sigma}$ is von Mises effective stress,

$$
\vec{\sigma}=\left(\frac{3}{2} s_{i j} s_{i j}\right)^{1 / 2}
$$


${ }^{-c}$ is the effective creep strain rate,

$$
\frac{\dot{e} c}{c}=A_{0}(\bar{\sigma})^{m}{ }^{m}(E)\left(m_{2}-1\right)
$$

$E$ is the effective time, which can be determined iteratively, and $A_{0}, m_{1}$, and $m_{2}$ are given constants. Equation (11) is derived from the uniaxial creep law, which has been generalized to multiaxial conditions by utilizing the effective stress and effective creep strain. Other creep laws could be employed in a similar manner.

The final inelastic strain rate can be written as

or

$$
\left.\begin{array}{l}
\dot{\varepsilon}_{i j}=\dot{\varepsilon}_{i j}^{p}+\dot{\varepsilon}_{i j}^{c} \\
\dot{\varepsilon}_{i j}=(\Psi+I) S_{i j}
\end{array}\right\}
$$

Unified Viscoplastic Theory

The new theories to characterize material behavior at high temperatures are known as unified theories, in the sense that plastic and creep strains are considered as arising from the same physical mechanism. One or more state variables are introduced in the constitutive equations. Again a small displacement and small strain formulation is used, with the total strain rate $\dot{\varepsilon}_{i j}$ decomposed into elastic $\dot{\varepsilon}_{i j}^{e}$ and inelastic $\dot{\varepsilon}_{i j}^{\dagger}$ parts,

$$
\dot{\varepsilon}_{i j}=\dot{\varepsilon}_{i j}^{e}+\dot{\varepsilon}_{i j}^{j}
$$

The relation between the elastic strain rate and the stress rate $\dot{\sigma}_{i j}$ is given Hooke's law (see Eqs. (2) and (3)).

The general form of the unified viscoplastic constitutive equations can be written as, 


$$
\begin{aligned}
& \dot{\varepsilon}_{i j}^{i}=\frac{A_{1} f^{n}\left(s_{i j}-\frac{2}{3} \Omega_{i j}\right)}{B} \\
& \dot{\Omega}_{i j}=A_{2} \dot{\varepsilon}_{i j}^{i}-\dot{G}_{i j} \\
& \dot{K}=A_{3} \dot{R}-\dot{j}\left(k-K_{0}\right)
\end{aligned}
$$

where $\Omega_{i j}$ and $K$ are the new state variables. The $\Omega_{i j}$ is defined as the back (equilibrium) stress tensor, and $K$ is the drag stress. The $\dot{R}$ and $B$ are written as

$$
\begin{gathered}
\dot{R}=\left(\frac{2}{3} \dot{\varepsilon}_{i j}^{i} \dot{\varepsilon}_{i j}\right)^{1 / 2} \\
B=\left[\frac{3}{2}\left(S_{i j}-\frac{2}{3} \Omega_{i j}\right)\left(S_{i j}-\frac{2}{3} \Omega_{i j}\right)\right]^{1 / 2}
\end{gathered}
$$

The $f^{n}$ is a function of $B / K$ to the power $n$, where $A_{1}, A_{2}$, and $n$ are material parameters, $A_{3}$ is the strain hardening function, and $\dot{G}$ and $\dot{j}$ are recovery functions.

Equation (14) is the flow law defining inelastic strain rate as a function of applied stress, state variables, and temperature; this function was selected to represent creep curves. As a result, three extensively used functions in creep theories namely power, exponential, and hyperbolic sine functions, are adopted in the unified viscoplastic theories. Of these, the power function has been broadly used because of its numerical simplicity.

Equations (15) and (16) are known as evolutionaly equations and are generally written in the context of a hardening and recovery form. The strain hardening function varies according to the value of the inelastic strain rate. The recovery function can be divided into dynamic and static recovery components. 
In this report, the specific constitutive equations proposed by walker (1976, 1980, 1981), Krleng-Swearengen-Rohde (1978), and Miller (1976) were used to test the new integration scheme; their equations are given in detail in Appendixes $A, B$, and $C$, respectively.

Self-Adaptive Forward Euler Integration Algorithm

Since the constitutive equations presented in the previous sections represent a system of first-order nonlinear differential equations, they can be written in a compact form, with the assumption that the stress and strain field are known at a given time $t$, as

$$
\dot{y}=f(y, t)
$$

where $y$ represents the vectors of stress ( $E q .(2))$, inelastic strain (Eq. (12) or (14)), back stress (Eq. (15)), drag stress (Eq. (16)); and $f(y, t)$ is an abbreviation for the nonlinear functions on the right side of these constitutive equations. These differential equations are, in general, highly nonlinear and have stiff regimes, particularly in the viscoplastic theory. Consequently, a very small time step is often required in order to use standard numerical integration techniques to solve these equations without loss of stability.

Varlous numerical integration methods have been proposed for solving siffness problems. Most of them are, however, intended for fields other than structural mechanics. For example, Gear (1971) developed a program for handling a general class of stiffness. Although Gear's methods have been successfully appilied to uniaxial one-element analysis (Miller, 1975), his package is not suitable for a large-scale finite element analysis because of its extensive computer time and storage requirement.

In the context of finite element analysis of rate-related problems, a number of numerical methods have been recommended. Numerical comparisons were 
extensively performed by Chang (1985) and Lindholm et al. (1985a, 1985b). The SAFE method has been found to be computationally efficient, especially when connected with the subincremental approach (Cassenti, 1983a, 1983b). The most significant advantage of this approach is that the numerical instability incurred in using an explicit method has been diminished in such a way that no reduction in gobal step size is necessary. The local step size is adjusted on the basis of a comparison between an estimated error and prescribed error bounds. This scheme is used for comparison purposes in the section Numerical Examples and Comparisons. The details of the scheme follow.

For the solution of Eq. (19), the initial values $y(t=0)=y_{A}$ have to be prescribed. The numerical solution is performed in discrete time steps $\Delta t$, starting from a known solution at time $t$. This time step $\Delta t$ is the current finite element global load increment and is divided into NSPLIT equal subincrements. The integration of the system in Eq. (19) is then performed by using forward differences with a smaller step size as

$$
y_{t+\Delta t}=y_{t}+\left(\frac{\Delta t}{N S P L I T}\right) f(t)
$$

The above equation is repeated NSPLIT times and the solution of $y$ at time $t+\Delta t$ is obtained. There are three possible ways to determine NSPLIT, depending on the magnitude of the change in a strain measure for every subincrement. The change in the strain measure is defined as

$$
E R R O R=\Delta R+\frac{\left(3 \Delta \mathrm{J}_{2}\right)^{1 / 2}}{2 \mu}
$$

where

$$
\begin{gathered}
\Delta R=\left(\frac{2}{3} \Delta \varepsilon_{i j}^{i} \Delta \varepsilon_{i j}^{i}\right)^{1 / 2} \\
\Delta J_{2}=\frac{3}{2} \Delta S_{i j} \Delta S_{i j}
\end{gathered}
$$


If the value of ERROR is between the specifled tolerances, usually $1 \times 10^{-4}$ and $1 \times 10^{-5}$ (defined as ERRORI in the section on numerical examples), then there is no change in NSPLIT for the next subincrement. However if ERROR is less than the upper bound tolerance, NSPLIT is reduced by half. When ERROR is greater than the lower bound tolerance, NSPLIT is doubled and the current subincrement step is repeated. If NSPLIT exceeds the maximum number specified, the conventional explicit forward Euler scheme is exploited with a fixed number of subincrements throughout. This scheme, often called "successive substitution" requires that a very small time step be enforced in stiff regions to avoid numerical instability. Note that this is not an iterative scheme. INTEGRAL FORMS OF ELASTO-PLASTIC-CREEP AND UNIFIED VISCOPLASTIC CONSTITUTIVE EQUATIONS

The fundamental concept in deriving a uniformly valid asymptotic integration scheme is to convert the constitutive differential equations presented in the preceding section into integral form. In this section the procedure for transforming a differential form into an integral form is presented for elasto-plastic-creep and unified viscoplastic theories. Elasto-Plastic-Creep Constitutive Integrated Equations

The inelastic strain rate tensor is written in the form of the deviatoric strain rate tensor $\dot{e}_{i j}$ as

$$
\dot{\varepsilon}_{i j}=\dot{e}_{i j}-\left(\frac{\dot{S}_{i j}}{2 \mu}\right)
$$

where

$$
\dot{e}_{i j}=\dot{\varepsilon}_{i j}-\left(\frac{\delta_{i j} \dot{\varepsilon}_{k k}}{3}\right)
$$

From Eq. (12), define 


$$
\frac{\dot{Q}}{2 \mu}=\Psi+\Gamma
$$

then

$$
\dot{\varepsilon}_{i j}^{i}=\left(\frac{\dot{Q}}{2 \mu}\right) s_{i j}
$$

Substitution of Eq. (27) into Eq. (17) yields

$$
\dot{R}=\left(\frac{\dot{Q}}{3 \mu}\right)\left(\frac{3}{2} s_{i j} s_{i j}\right)^{1 / 2}=\left(\frac{\dot{Q}}{3 \mu}\right) \bar{\sigma}
$$

or

$$
\dot{Q}=\frac{3 \mu \dot{R}}{\bar{\sigma}}
$$

Equating Eqs. (24) and (27) ylelds

$$
2 \mu \dot{e}_{i j}-\dot{S}_{i j}=\dot{Q S}_{i j}
$$

Rearrange the above equation to give a form of a first-order differential equation

$$
\dot{S}_{i j}+\dot{Q S}_{i j}=2 \mu \dot{e}_{i j}
$$

Integrating Eq. (30) for $S_{i j}$ at time $t$ yields

$$
S_{i j}(t)=S_{i j}(0) \exp [-Q(t)]+\int_{\xi=0}^{t} \exp \left[-\int_{\tau=\xi}^{t} \frac{\partial Q(\tau)}{\partial \tau} d \tau\right] 2 \mu \frac{\partial e_{i j}}{\partial \xi} d \xi
$$

Since at $t=0, S_{i j}(0)=0$; and $e_{i j}=\varepsilon_{i j}-\delta_{i j} \varepsilon_{k k} / 3$; then Eq. (31) becomes the final integral form of Eq. (27)

$\sigma_{i j}(t)=\left(\lambda+\frac{2}{3} \mu\right) \delta_{i j} \varepsilon_{k k}(t)+\int_{\xi=0}^{t} \exp \{-[Q(t)-Q(\xi)]\}\left(2 \mu \frac{\partial \varepsilon_{i j}}{\partial \xi}-\frac{2 \mu}{3} \delta_{i j} \frac{\partial \varepsilon_{k k}}{\partial \xi}\right) d \xi$

where 


$$
Q(t)=\int_{\xi=0}^{t} \frac{3 \mu \partial R}{\bar{\sigma} \partial \xi} d \xi
$$

and

$$
R(t)=\int_{\xi=0}^{t}\left(\frac{2}{3} \frac{\partial \varepsilon_{i j}^{i}}{\partial \xi} \frac{\partial \varepsilon_{i j}^{i}}{\partial \xi} d \xi\right)^{1 / 2}
$$

Equation (32) represents the integral form of the differential equation defined by Eq. (12), and it has a new scalar parameter $Q$. Unified Viscoplastic Constitutive Integrated Equations

Each state variable in the differential form of viscoplastic relations presented in the section Unified Viscoplastic Theory is converted into the integral form by using a procedure similar to that for elasto-plastic creep. Miller's model with three state variables demonstrates these transformations. Inelastic strain. - The inelastic strain rate tensor is

$$
\dot{\varepsilon}_{i j}^{i}=\frac{3}{2} B \theta^{\prime}\left[\sinh \left(\frac{2}{k}\right)^{3 / 2}\right]^{n} \frac{\left(s_{i j}-\frac{2}{3} \Omega_{i j}\right)}{2}
$$

where

$$
Z=\left[\frac{2}{3}\left(\frac{3}{2} s_{i j}-\Omega_{i j}\right)\left(\frac{3}{2} s_{i j}-\Omega_{i j}\right)\right]^{1 / 2}
$$

$B$ is a material constant, and $\theta^{\prime}$ is defined in Appendix C. Equation (35) can be rewritten as

$$
\dot{\varepsilon}_{i j}^{i}=\frac{\dot{L}}{2 \mu}\left(s_{i j}-\frac{2}{3} \Omega_{i j}\right)
$$

where

$$
\frac{i}{2 \mu}=\frac{3 B \theta^{\prime}}{2 Z}\left[\sinh \left(\frac{Z}{K}\right)^{3 / 2}\right]^{n}
$$

The second invariant of the inelastic strain rate tensor is written as 


$$
\dot{R}=\left(\frac{2}{3} \varepsilon_{i j}^{i} \varepsilon_{i j}^{i}\right)^{1 / 2}
$$

Substitution of Eq. (37) into Eq. (39) gives

$$
\dot{R}=\frac{\dot{L}}{3 \mu} z
$$

From Eq. (40) the relation $z=3 \mu \dot{R} / \dot{L}$ may be substituted into the denominator of Eq. (38) to give

$$
\frac{\dot{L}}{2 \mu}=\frac{\dot{L}}{2 \mu} B \theta^{\prime} \frac{\left[\sinh \left(\frac{Z}{K}\right)^{3 / 2}\right]^{n}}{\dot{R}}
$$

from which the relation

$$
\dot{R}=B \theta^{\prime}\left[\sinh \left(\frac{z}{K}\right)^{3 / 2}\right]^{n}
$$

is obtained.

Notice that Eq. (4I) can be extracted directly from the right side of Eq. (35). Rearranging Eq. (41) gives

$$
z=k\left[\sinh ^{-1}\left(\frac{\dot{R}}{B \theta^{1}}\right)^{1 / n}\right]^{2 / 3}
$$

which, when substituted into Eq. (38), yields

$$
\dot{L}=\frac{3 \mu \dot{R}}{\left\{k\left[\sinh ^{-1}\left(\frac{\dot{R}}{B \theta^{\prime}}\right)^{1 / n}\right]^{2 / 3}\right\}}
$$

Equating Eq. (37) with Eq. (24) forms

$$
2 \mu \dot{e}_{i j}-\dot{S}_{i j}=\dot{L}\left(S_{i j}-\frac{2}{3} \Omega_{i j}\right)
$$

Let 
or

$$
\left.\begin{array}{l}
y_{i j}=s_{i j}-\frac{2}{3} \Omega_{i j} \\
\dot{y}_{i j}=\dot{s}_{i j}-\frac{2}{3} \dot{\Omega}_{i j}
\end{array}\right\}
$$

Then Eq. (44) becomes

$$
\dot{y}_{i j}+\dot{L y}_{i j}=2 \mu \dot{e}_{i j}-\frac{2}{3} \dot{\Omega}_{i j}
$$

Equation (46) is in the form of a first-order differential equation and can be integrated as

$y_{i j}(t)=y_{i j}(0) \exp [-L(t)]+\int_{\xi=0}^{t} \exp \left\{-\int_{\tau=\xi}^{t}\left[\frac{\partial L(\tau)}{\partial \tau}\right] d \tau\right\}\left(2 \mu \frac{\partial e_{i j}}{\partial \xi}-\frac{2 \partial \Omega_{i j}}{3 \partial \xi}\right) d \xi$

where $y_{i j}(0)$ is the initial value. If $S_{i j}(0)=0$ and $\Omega_{i j}(0)=0$, then $y_{i j}(0)=0$. By substituting Eq. (45) and the properties of deviatoric stress and strain into Eq. (47), it can be written as

$$
\begin{aligned}
\sigma_{i j}(t)=\frac{2}{3} \Omega_{i j}(t)+\left(\lambda+\frac{2}{3} \mu\right) \delta_{i j} \varepsilon_{k k}(t) & +\int_{\xi=0}^{t} \exp \{-[L(t)-L(\xi)]\} \\
& \times\left(2 \mu \frac{\partial \varepsilon_{1 j}}{\partial \xi}-\frac{2 \mu}{3} \delta_{i j} \frac{\partial \varepsilon_{k k}}{\partial \xi}-\frac{2 \partial \Omega_{i j}}{3 \partial \xi}\right) d \xi
\end{aligned}
$$

where

$$
L(t)=\int_{\xi=0}^{t} \frac{3 \mu\left(\frac{\partial R}{\partial \xi}\right)}{\left\{K\left[\sinh ^{-1}\left(\frac{\frac{\partial R}{\partial \xi}}{B \theta^{\prime}}\right)^{1 / n}\right]^{2 / 3}\right\}} d \xi
$$


Back stress. - The back stress in differential form is

$$
\dot{\Omega}_{i j}=H_{1} \dot{\varepsilon}_{i j}^{i}-H_{1} B \theta^{\prime} \frac{\left\{\sinh \left[A_{1}\left(\frac{2}{3} \Omega_{i j} \Omega_{i j}\right)^{1 / 2}\right]\right\}^{n} \Omega_{i j}}{\left(\frac{2}{3} \Omega_{i j} \Omega i j\right)^{1 / 2}}
$$

where

$$
\theta^{\prime}=\exp \left(-\frac{Q^{\star}}{k T}\right) \quad \text { for } T \geq 0.6 T_{m}
$$

and

$$
\theta^{\prime}=\exp \left\{-\frac{Q^{*}}{0.6 \mathrm{kT}}\left[\ln \left(\frac{0.6 T_{m}}{T}\right)+1\right]\right\} \text { for } T<0.6 T_{m}
$$

The symbols $n, H_{1}, A_{1}, B, Q^{*}$, and $k$ are material constants independent of temperature; $T$ is the temperature in Kelvin, and $T_{m}$ is the melting temperature of the material. We can rewrite Eq. (50) into a first-order differential equation as

$$
\dot{\Omega}_{i j}+\dot{G}_{i j}=H_{1} \dot{\varepsilon}_{i j}^{1}
$$

where

$$
\dot{G}=H_{1} B \theta^{\prime} \frac{\left\{\sinh \left[A_{1}\left(\frac{2}{3} \Omega_{i j} \Omega_{i j}\right)^{1 / 2}\right]\right\}^{n}}{\left(\frac{2}{3} \Omega_{i j} \Omega_{i j}\right)^{1 / 2}}
$$

Equation (51) can be integrated to give

$$
\Omega_{i j}(t)=\int_{\xi=0}^{t} H_{1} \exp \{-[G(t)-G(\xi)]\} \frac{\partial \varepsilon_{i j}^{i}}{\partial \xi} d \xi
$$

where $\Omega_{i j}(t)=0$ at $t=0$, and 


$$
G(t)=\int_{\xi=0}^{t}\left[H_{1} B \theta^{\prime} \frac{\left\{\sinh \left[A_{1}\left(\frac{2}{3} \Omega_{i j} \Omega_{i j}\right)^{1 / 2}\right]\right\}^{n}}{\left(\frac{2}{3} \Omega_{i j} \Omega_{i j}\right)^{1 / 2}}\right] d \xi
$$

Dragstress. - The final state variable of Miller's theory is the drag stress and is defined in differential form as

$$
\dot{K}=H_{2} \dot{R}\left[C_{2}+\left(\frac{2}{3} \Omega_{i j} \Omega_{i j}\right)^{1 / 2}-\frac{A_{2}}{A_{1}} K^{3}\right]-H_{2} C_{2} B \theta^{\prime}\left[\sinh \left(A_{2} K^{3}\right)\right]^{n}
$$

where $\mathrm{H}_{2}, \mathrm{C}_{2}$, and $A_{2}$ are material constants and independent of temperature. Again Eq. (55) can be rearranged into the first-order differential equation as

$$
\dot{K}+\dot{J}\left(K-K_{0}\right)=H_{2} \dot{R}\left[C_{2}+\left(\frac{2}{3} \Omega_{i j} \Omega_{i j}\right)^{1 / 2}-\frac{A_{2}}{A_{1}} K^{3}\right]
$$

where

$$
\dot{j}=H_{2} C_{2} B \theta^{\prime} \frac{\left[\sinh \left(A_{2} K^{3}\right)\right]^{n}}{\left(K-K_{0}\right)}
$$

Integrating $E q$. (56) under the initial condition $K(t)=K_{0}$ at $t=0$ gives

$K(t)=K_{0}+\int_{\xi=0}^{t} H_{2}\left[C_{2}+\left(\frac{2}{3} \Omega_{i j} \Omega_{1 j}\right)^{1 / 2}-\frac{A_{2}}{A_{1}} K^{3}\right] \exp [-J(t)-J(\xi)] \frac{\partial R}{\partial \xi} d \xi$

where

$$
J(t)=\int_{\xi=0}^{t} H_{2} C_{2} B \theta^{\prime} \frac{\left[\sinh \left(A_{2} K^{3}\right)\right]^{n}}{\left(K-K_{0}\right)} d \xi
$$

A UNIFORMLY VALID ASYMPTOTIC EXPANSION INTEGRATION ALGORITHM

With the integrated form of each state variable presented in the previous section, the asymptotic expansion can now be used to represent each integral 
of both the elastic-plastic creep and the unified viscoplastic theories. The final forms appear in recursive relations and need to be solved by a NewtonRaphson iterative technique.

Elastic-Plastic-Creep Uniformly Valid Asymptotic Expansion

Equation (32) written at time $t+\Delta t$ can be shown as

$$
\sigma_{i j}(t+\Delta t)=\left(\lambda+\frac{2}{3} \mu\right) \delta_{i j} \varepsilon_{k k}(t+\Delta t)+I_{i j}(t+\Delta t)
$$

where

$$
I_{i j}(t+\Delta t)=\int_{\xi=0}^{t+\Delta t} \exp \{-[Q(t+\Delta t)-Q(\xi)]\}\left(2 \mu \frac{\partial \varepsilon_{i j}}{\partial \xi}-\frac{2 \mu}{3} \delta_{i j} \frac{\partial \varepsilon_{k k}}{\partial \xi}\right) d \xi
$$

Because of incremental formulation in nonlinear analysis, Eq. (61) can be separated into two parts as

$$
I_{i j}(t+\Delta t)=I_{i j}^{\prime}(t)+I_{i j}^{\prime}(\Delta t)
$$

where

$$
\begin{aligned}
& I_{i j}^{\prime}(t)=\int_{\xi=0}^{t} \exp \{-[Q(t+\Delta t)-Q(\xi)]\} \exp [Q(t)] \exp [-Q(t)] \\
& \times\left(2 \mu \frac{\partial \varepsilon_{i j}}{\partial \xi}-\frac{2 \mu}{3} \delta_{i j} \frac{\partial \varepsilon_{k k}}{\partial \xi}\right) d \xi
\end{aligned}
$$

and

$$
I_{i j}^{\prime}(\Delta t)=\int_{\xi=t}^{t+\Delta t} \exp \{-[Q(t+\Delta t)-Q(\xi)]\}\left(2 \mu \frac{\partial \varepsilon_{i j}}{\partial \xi}-\frac{2 \mu}{3} \delta_{i j} \frac{\partial \varepsilon_{k k}}{\partial \xi}\right) d \xi
$$

The unity expression $\left[e^{Q(t)} e^{-Q(t)}\right]$ is introduced into Eq. (63) to give

$$
\begin{aligned}
I_{i j}^{\prime}(t)=\exp \{-[Q(t+\Delta t)-Q(t)]\} & \int_{\xi=0}^{t} \exp \{-[Q(t)-Q(\xi)]\} \\
& \times\left(2 \mu \frac{\partial \varepsilon_{i j}}{\partial \xi}-\frac{2 \mu}{3} \delta_{i j} \frac{\partial \varepsilon_{k k}}{\partial \xi}\right) d \xi
\end{aligned}
$$


From Eqs. (60) and (61), the right side of Eq. (65) can be identified as $I_{i j}(t)$; thus

or

$$
I_{i j}^{\prime}(t)=\exp (-\Delta Q) I_{i j}(t)
$$

where

$$
\Delta Q=Q(t+\Delta t)-Q(t) \cong \dot{Q}(t+\Delta t) \Delta t
$$

The only integral in Eq. (62) is now $I_{i j}^{\prime}(\Delta t)$. According to Eq. (A6) in Appendix A (Walker, 1987), this integral can be represented by a uniformly valid asymptotic form. If only the first term of Eq. (A6) is used, the approximated recursive relation of $\mathrm{Eq}$. (64) is

$$
I_{i j}^{\prime}(\Delta t)=\left(2 \mu \Delta \varepsilon_{i j}-\frac{2}{3} \mu \delta_{i j} \Delta \varepsilon_{k k}\right)\left[\frac{1-\exp (-\Delta Q)}{\Delta Q}\right]
$$

where

$$
\Delta \varepsilon_{i j}=\varepsilon_{i j}(t+\Delta t)-\varepsilon_{i j}(t)
$$

and

$$
\begin{aligned}
\Delta Q & =\dot{Q}(t+\Delta t) \Delta t \\
& =\frac{3 \mu \Delta t}{\bar{\sigma}(t+\Delta t)} \dot{R}(t+\Delta t)
\end{aligned}
$$

The asymptotic recursive form of Eq. (60) becomes

$$
\begin{aligned}
\sigma_{i j}(t+\Delta t)=\left(\lambda+\frac{2}{3} \mu\right) \delta_{i j} \varepsilon_{k k}(t & +\Delta t)+\exp (-\Delta Q)\left[\sigma_{i j}(t)-\left(\lambda+\frac{2}{3} \mu\right) \delta_{i j} \varepsilon_{k k}(t)\right] \\
& +\left(2 \mu \Delta \varepsilon_{i j}-\frac{2}{3} \mu \delta_{i j} \Delta \varepsilon_{k k}\right)\left[\frac{1-\exp (-\Delta Q)}{\Delta Q}\right]
\end{aligned}
$$


Unified Viscoplastic Uniformly Valid Asymptotic Expansion

A procedure simllar to that for the elasto-plastic-creep model is used to obtain the final UVAE recursive forms of viscoplastic model for all three state varlables, namely, Cauchy stress, back stress, and drag stress.

For Cauchy stress, the relationship is

$$
\begin{aligned}
\sigma_{i j}(t+\Delta t)=\frac{2}{3} \Omega_{i j}(t & +\Delta t)+\left(\lambda+\frac{2}{3} \mu\right) \delta_{i j} \varepsilon_{k k}(t+\Delta t) \\
& +\exp (-\Delta Q)\left[\sigma_{i j}(t)-\frac{2}{3} \Omega_{i j}(t)-\left(\lambda+\frac{2}{3} \mu\right) \delta_{i j} \varepsilon_{k k}(t)\right] \\
& +\left(2 \mu \Delta \varepsilon_{i j}-\frac{2}{3} \mu \delta_{i j} \Delta \varepsilon_{k k}-\frac{2}{3} \Delta \Omega_{i j}\right)\left[\frac{1-\exp (-\Delta Q)}{\Delta Q}\right]
\end{aligned}
$$

where

$$
\begin{aligned}
& \Delta \varepsilon_{i j}=\varepsilon_{i j}(t+\Delta t)-\varepsilon_{i j}(t) \\
& \Delta \Omega_{i j}=\Omega_{i j}(t+\Delta t)-\Omega_{i j}(t)
\end{aligned}
$$

and

$$
\Delta Q=\dot{Q}(t+\Delta t) \Delta t=\frac{3 \mu \dot{R}(t+\Delta t)}{K(t+\Delta t)} \frac{\Delta t}{\left[\sinh ^{-1}\left(\frac{\dot{R}}{B \theta^{\prime}}\right)^{1 / n}\right]^{2 / 3}}
$$

For back stress, the relationship is

$$
\Omega_{i j}(t+\Delta t)=\exp (-\Delta G) \Omega_{i j}(t)+H_{1} \Delta \varepsilon_{i j}^{i}\left[\frac{1-\exp (-\Delta G)}{\Delta G}\right]
$$

where

$$
\begin{aligned}
\Delta \varepsilon_{i j}^{i} & =\varepsilon_{i j}^{i}(t+\Delta t)-\varepsilon_{i j}^{j}(t) \\
\varepsilon_{i j}^{j}(t+\Delta t) & =e_{i j}(t+\Delta t)-\left[\frac{S_{i j}(t+\Delta t)}{2 \mu}\right]
\end{aligned}
$$

and 


$$
\Delta G=H_{1} B \theta^{\prime} \frac{\left(\sinh \left\{A_{1}\left[\frac{2}{3} \Omega_{i j}(t+\Delta t) \Omega_{i j}(t+\Delta t)\right]^{1 / 2} j\right)^{n} \Delta t\right.}{\left[\frac{2}{3} \Omega_{i j}(t+\Delta t) \Omega_{i j}(t+\Delta t)\right]^{1 / 2}}
$$

Finally for drag stress, the relationship is

$$
\begin{aligned}
K(t+\Delta t)=K_{0}+\left[K(t)-K_{0}\right] \exp (-\Delta J)+H_{2}\left\{C_{2}\right. & +\left[\frac{2}{3} \Omega_{i j}(t+\Delta t) \Omega_{i j}(t+\Delta t)\right]^{1 / 2} \\
& \left.-\frac{A_{2}}{A_{1}} K^{3}(t)\right\} \Delta R\left[\frac{1-\exp (-\Delta J)}{\Delta J}\right]
\end{aligned}
$$

where

$$
\begin{gathered}
\Delta J=\frac{\Delta t}{\left[K(t)-K_{0}\right]}\left(H_{2} C_{2} B \theta^{\prime}\left\{\sinh \left[A_{2} K^{3}(t)\right]\right\}^{n}\right) \\
\Delta R=\dot{R}(t+\Delta t) \Delta t
\end{gathered}
$$

Newson-Raphson Iteration

Unltke the forward Euler integration scheme, Eqs. (70), (71), (73), and (75) are recursive in nature. Each unknown state variable at time $t+\Delta t$ involves a single parameter (i.e., $\Delta Q, \Delta G$, or $\Delta J$ ) which, in turn, requires a knowledge of the parameter's unknown state variable. These equations are the recursive or implicit equations. Therefore a technique such as the NewtonRaphson iteration is required. However this Newton-Raphson implicit iterative scheme is different from the implicit integration scheme of differential equations (Chang, 1985) in that its Jacobian matrix is much smaller. For the elasto-plastic-creep theory, instead of iterating over six components of Cauchy stress, Eq. (70) iterates over one parameter, $\Delta Q$. In the case of unified viscoplastic theory, the size of the Jacobian matrix is reduced from $13 \times 13$ ( 1 ix components of Cauchy stress, six of back stress, and one of drag stress) to $3 \times 3(\Delta Q, \Delta G$, and $\Delta J)$; this is the tremendous advantage of transforming 
differential equations to UVAE equations. Since the Jacobian matrix of the elasto-plastic-creep model is a subset of that of the viscoplastic model, the latter will be used to demonstrate the Newton-Raphson technique.

The governing iterative equations are obtained from Eqs. (72), (74), and (76) for each state variable and written in the function forms as

$$
\left.\begin{array}{c}
f_{1}(\Delta Q, \Delta G, \Delta J)=\Delta Q-\frac{3 \mu \dot{R}(t+\Delta t)}{K(t+\Delta t)} \frac{\Delta t}{\left[\sinh ^{-1}\left(\frac{\dot{R}}{B \theta^{\prime}}\right)^{1 / n}\right]^{2 / 3}} \\
f_{2}(\Delta Q, \Delta G, \Delta J)=\Delta G-H_{1} B \theta^{\prime}\left(\sinh \left\{A_{1}\left[\frac{2}{3} \Omega_{i j}(t+\Delta t) \Omega_{i j}(t+\Delta t)\right]^{1 / 2}\right\}^{n}\right) \\
f_{3}(\Delta Q, \Delta G, \Delta J)=\Delta J-\frac{\Delta t}{\left[K(t)-K_{0}\right]}\left(H_{2} C_{2} B \theta^{\prime}\left\{\sinh \left[A_{2} K^{3}(t)\right]\right\}^{n}\right)
\end{array}\right\}
$$

The iteration starts with judiciously chosen initial guesses for $\Delta Q, \Delta G$, and $\Delta \mathrm{J}$. The intent is to find the solution of the equations

$$
f_{m}(\Delta Q, \Delta G, \Delta J)=0
$$

or

$$
f_{m}\left(\Delta u_{j}\right)=0
$$

where $m=1,2,3$ and $\Delta U_{j}$ is a vector of $\Delta Q, \Delta G$, and $\Delta J$. Equation (78) represents a system of nonlinear equations. The most frequently used iteration scheme for the solution of these equations is some form of a Newton-Raphson iteration (Stricklin et al., 1973; Oden, 1972; Bergan et al., 1978). By using a Taylor series expansion and retainning only the first-order term, the iterative form of Eq. (78) is written as 


$$
f_{m}\left(\Delta U_{j}\right)=f_{m}\left(\Delta U_{j}^{j-1}\right)+\left(\frac{\partial f_{m}}{\partial \Delta U_{j}}\right)_{\Delta U_{j}^{j-1}}\left(\Delta U_{j}-\Delta U_{j}^{i-1}\right)=0
$$

Let

$$
U^{i}=\Delta U_{j}-\Delta U_{j}^{i-1}
$$

and

$$
\left(\frac{\partial f_{m}}{\partial \Delta U_{j}}\right)_{\Delta U_{j}^{i-1}}=\left(M_{m j}\right)^{i-1}
$$

The matrix $\left(M_{m j}\right)^{i-1}$ is called a Jacobian matrix with a maximum size of $3 \times 3$. Thus Eq. (79) can be written as

$$
\left(M_{m j}\right)^{i-1} U^{i}=-f_{m}\left(\Delta U_{j}^{i-1}\right)
$$

Since Eq. (79) represents a Taylor series approximation, the incremental correction $U^{j}$ is used to obtain the next approximation

$$
\Delta u_{j}^{i}=\Delta u_{j}^{i-1}+U^{i}
$$

The relations in Eqs. (81) and (82) constitute the Newton-Raphson solution of Eq. (78). The iteration is continued until appropriate convergence criteria, discussed in the section Finite Element Formulation and Overall Scheme, are satisfied.

The Jacobian matrix $\left(M_{m j}\right)^{i-1}$ can be evaluated by finite difference perturbation techniques and placed in the following form 


$$
\left.\begin{array}{l}
M_{m 1}=\frac{\left[f_{m}(\Delta Q+d Q, \Delta G, \Delta J)-f_{m}(\Delta Q, \Delta G, \Delta J)\right]}{d Q} \\
M_{m 2}=\frac{\left[f_{m}(\Delta Q, \Delta G+d G, \Delta J)-f_{m}(\Delta Q, \Delta G, \Delta J)\right]}{d G} \\
M_{m 3}=\frac{\left[f_{m}(\Delta Q, \Delta G, \Delta J+d J)-f_{m}(\Delta Q, \Delta G, \Delta J)\right]}{d J}
\end{array}\right\}
$$

where

$$
\begin{aligned}
m & =1,2,3 \\
d Q & =(0.01) \Delta Q, \\
d G & =(0.01) \Delta G, \\
d J & =(0.01) \Delta J .
\end{aligned}
$$

\section{COUPLED CONTINUUM DAMAGE AND VISCOPLASTIC FORMULATION}

The nucleation of microcavities, and their growth and coalescence into macroscopic cracks, is generally the cause of material deterioration (material damage) such as decrease of strength, rigidity, toughness, stability, and residual life. Since the pionee works of Kachanov (1958) and Rabotnov (1969), a new concept has been developed to investigate the growth of microcavities and the mechanical behavior of damaged materials. This concept, called "continuum damage mechanics," represents the effects of distributed cavities in terms of certain mechanical variables. Since its notion hypothesizes that the effects of microcavities can be described by appropriate damage variables, such variables can be represented according to the same notion as that of stress, strain, or temperature field (Murakami, 1983). Therefore they are the same as the internal state variables in thermodynamical theories of constitutive equations.

In this section we introduce a damage variable as an internal state variable and couple it with the constitutive and evolution equations of 
Walker's viscoplastic theory. Our atm is to demonstrate the potential advantage of the proposed integration scheme when investigating continuum damage models. Walker's damage model, which was selected for this exercise, is first presented in differential form and then in uniformly valid asymptotic form. Note that a damaged state is not considered in the elastic constitutive equations.

The concept of a damage variable was first proposed by Kachanov (1974) when he developed a mathematical model for evaluating creep rupture times. Cavity growth that results in a reduction of the net area is assumed to be the principal mechanism of material damage. The damage state may be represented by an internal state variable $\psi$ such that $\psi=1$ and $\psi=0$ specify the undamaged initial state and the final rupture state, respectively. By taking the maximum effective stress $\bar{\sigma}$ as the principal factor governing the progression of the damage, Kachanov formulated the evolution equation of the damage variable $\psi$ as follows:

$$
\dot{\psi}=-A\left(\frac{\bar{\sigma}}{\psi}\right)^{r}
$$

where $A$ and $r$ are material constants. Though Kachanov did not discuss the physical meaning of $\psi$, it may be interpreted as the ratio between the net area $S_{n}$ of a given section to that of the corresponding apparent area $S$

$$
\psi=\frac{S_{n}}{S}
$$

The stress, which is magnified by the net area reduction, is called net stress and is defined

$$
\sigma_{\mathrm{n}}=\frac{\sigma}{\psi}
$$

As in the classical theories of creep, Eq. (88) can be generalized to multiaxial stress states. Assuming isotropy of material and of material 
damage, we, for demonstration purpose, introduce $\psi$ to Walker's viscoplastic model and derive the following equations:

$$
\begin{aligned}
& \dot{\varepsilon}_{i j}=\left\{\frac{\left[\frac{2}{3}\left(\frac{3}{2} s_{i j}-\Omega_{i j}\right)\left(\frac{3}{2} s_{i j}-\Omega_{i j}\right)\right]^{1 / 2}}{4 K}\right\}^{n} \frac{\left(\frac{3}{2} s_{i j}-\Omega_{i j}\right)}{\left[\frac{2}{3}\left(\frac{3}{2} s_{i j}-\Omega_{i j}\right)\left(\frac{3}{2} s_{i j}-\Omega_{i j}\right)\right]^{1 / 2}} \\
& \dot{\Omega}_{i j}=\left(n_{1}+n_{2}\right) \dot{\varepsilon}_{i j}^{j}-\left(\Omega_{i j}-\dot{\Omega}_{i j}-n_{i} \varepsilon_{i j}^{i}\right) \\
& x\left\{\left[n_{3}+n_{4} \exp \left(-n_{5} R\right)\right] \dot{R}+n_{6}\left(\frac{2}{3} \Omega_{i j} \Omega_{i j}\right)^{(m-1) / 2}\right\} \\
& \dot{\psi}=-A\left(\frac{\bar{\sigma}}{\psi}\right)^{r}
\end{aligned}
$$

where

$$
\bar{\sigma}=\left(\frac{3}{2} S_{i j} S_{i j}\right)^{1 / 2}
$$

$n_{1}, n_{2}, n_{3}, n_{4}, n_{5}, n_{6}, m, A$, and $r$ are material constants.

The UVAE form of Eqs. (89) and (90) is obtained in a fashion similar to that already described. However, the damage parameter is derived by directly integrating Eq. (86). The final form is as follows:

$$
\begin{aligned}
\sigma_{i j}(t+\Delta t)=\frac{2}{3} \Omega_{i j}(t & +\Delta t)+\left(\lambda+\frac{2}{3} \mu\right) \delta_{i j} \varepsilon_{k k}(t+\Delta t) \\
& +\exp (-\Delta Q)\left[\sigma_{i j}(t)-\frac{2}{3} \Omega_{i j}(t)-\left(\lambda+\frac{2}{3} \mu\right) \delta_{i j} \varepsilon_{k k}(t)\right] \\
& +\left(2 \mu \Delta \varepsilon_{i j}-\frac{2}{3} \mu \delta_{i j} \Delta \varepsilon_{k k}-\frac{2}{3} \Delta \Omega_{i j}\right)\left[\frac{1-\exp (-\Delta Q)}{\Delta Q}\right]
\end{aligned}
$$

where

$$
\Delta Q=\frac{3 \mu \dot{R}(t+\Delta t)^{1-(1 / n)}}{\psi K(t+\Delta t)} \Delta t
$$

27 


$$
\begin{gathered}
\Omega_{i j}(t+\Delta t)=\exp (-\Delta G)\left[\Omega_{i j}(t)-\stackrel{\circ}{\Omega}_{i j}\right]+n_{2} \Delta \varepsilon_{i j}^{i}\left[\frac{1-\exp (-\Delta G)}{\Delta G}\right] \\
\Delta G=\left\{n_{3} \dot{R}(t+\Delta t)+n_{6}\left[\frac{2}{3} \Omega_{k l}(t+\Delta t) \Omega_{k 1}(t+\Delta t)\right]^{(m-1) / 2}\right\} \Delta t \\
K(t+\Delta t)=k_{0} \\
\psi(t+\Delta t)=\left[1-A(r+1)(t+\Delta t) \bar{\sigma}^{r}\right]
\end{gathered}
$$

As mentioned earlier, the differential form of the unified viscoplastic formulation results in a mathematically stiff system of differential equations. When damage is incorporated, unstable behavior from the numerical integration tends to occur whether or not the explicit forward difference or the implicit backward difference method is used. This unstable phenomenon in the differential equations arises from the fact that the right side of Eq. (89) becomes very large and sensitive to the time-step increment as the damage parameter approaches zero. For the integral form of this damage model, the factor $\psi$ appears on the right side of Eq. (92), and this equation is the intermediate term of Eq. (91) for the stress. When $\psi$ approaches zero, $\Delta Q$ of Eq. (92) becomes large, and when $\Delta Q$ is substituted into Eq. (91), the stress decreases. There is no sign of numerical difficulty. Therefore, an unstable phenomenon should not be encountered if the proposed integration scheme is used to integrate the continuum damage model.

Both differential and UVAE forms of this coupled continuum damage and viscoplastic model have been incorporated into a MARC finite element program. The results are presented in the section Numerical Examples and Comparisons. FINITE ELEMENT FORMULATION AND OVERALL SCHEME

In the analysis of time-dependent constitutive relations, the formulation currently used is that for small strain theory; that is, material nonlinearity, only, is taken into consideration. In nonlinear finite element analysis, it is 
most effective to use an incremental formulation of the equation of motion. The global incremental governing equtions are given as

$$
[K]\{\Delta U\}^{i}=\{\Delta R\}^{i}
$$

where $\{\Delta U\}^{\mathfrak{l}}$ is the vector of increments in nodal point displacements, $\{\Delta R\}^{i}$ is the vector of unbalanced force at fteration $i$, and [K] is the global stiffness matrix and is defined as

$$
[K]=\int_{v}[B]^{\top}[C][B] d v
$$

where [B] is a strain-displacement transformation, and [C] is a stress-strain material property matrix.

There are two well-known methods to represent the inelastic strain of constitutive relations governing each element at the local level and to assemble this information into the global level of Eq. (97). The first approach, the tangent stiffness method, combines elastic and inelastic strain characteristics at each increment directly into a tangent modulus [C], which is then supplied to the global equations and assembled into the global stiffness matrix [K]. This approach is commonly employed with rate-independent constitutive equations (i.e., plasticity). The second approach is called the initial strain method wherein the tangent modulus $[C]$ is evaluated from the elastic material moduli only. The inelastic strain is carried to the global equations in the form of strain increments $\left\{\Delta \varepsilon^{\mathfrak{j}}\right\}$. These strain increments are then assembled into a pseudo-load vector $\left\{\Delta R^{\star}\right\}$ which is added to the right side of Eq. (97) and defined as

$$
\left\{\Delta R^{*}\right\}=\int_{v}[B]^{T}[C]\left\{\Delta \varepsilon^{i}\right\} d v
$$

This approach has been widely used with creep and unified viscoplastic constitutive equations and is employed throughout this work in the proposed 
integration scheme presented in the previous sections. A flow chart describing the nonlinear finite element analysis with a global incremental iteration procedure is presented in Fig. I

At the local level the overall scheme with a Newtom-Raphson iteration is summarized in Fig. 2. The basic concept behind this scheme is using the UVAE equations of viscoplastic models, derived previousiy while ensuring that by taking only the first term of the expansion, the açcuracy is obtained via Newton-Raphson iteration. Details are as follows:

(1) With the initial strain method, an inelastic strain increment is assumed at the start of iteration to be a deviatoric strain increment taken from the previous time step. However, for subsequent global iteration the deviatoric strain increment that is calculated from previous global iteration is used.

(2) The initial guesses for $\Delta Q, \Delta G$, and $\Delta J$, or so-called local iteration vectors, are all assumed to be 0.1 . These values are judiciously chosen on the basis of experience. The values range between 0.1 and 3.0 . For small and nonsevere loading problems, a high number is recommended; whereas for severe thermal and mechanical loading situations, a low number is more appropriate. The state variables $\sigma_{i j}, \Omega_{i j}$, and $K$ are then determined by using Eqs. (71), (73), and (75). Whenever the local iteration vector is updated, these state variables must be recalculated.

(3) To calculate the inelastic strain rate $\dot{R}$, the finite difference is employed by equating $\dot{R}$ to $\Delta R / \Delta t$, where $\Delta t$ is the current time-step increment and $\Delta R$ is determined as $\left[(2 / 3) \Delta \varepsilon_{i j}^{i} \Delta \varepsilon_{i j}^{i}\right]^{1 / 2}=$. For the first iteration, $\Delta \varepsilon_{i j}^{i}$ is set to $\Delta e_{i j}$. In the subsequent iterations, $\Delta \varepsilon_{i j}^{i}$ is set equal to $\Delta e_{i j}-\left(\Delta S_{i j} / 2 \mu\right)$. 
(4) Once the state variables are known cbased on the initial guess of the local iteration vector), the functions in Eq. (77) can be evaluated to determine how good the guess is. These functions will be the right side vector of Eq. (82). Obviously, if the guess is good, these functions will be small, and the local iteration vector computed from Eq. (82) will also be small. This is the sign of convergence.

(5) Next, the matrix $\left(M_{m j}\right)$ is estimated from Eq. (84). The finite difference perturbation technique is based on 1 percent of the values of $\Delta Q$, $\Delta G$, and $\Delta J$. This proved to be a viable choice since no ill conditioning of of the matrix took place during iterations.

(6) The iteration vector can now be corrected with Eq. (82) by inverting the matrix $\left(M_{m j}\right)$, whose maximum size is only $3 \times 3$ as in Miller's model. For elasto-plastic-creep model, the matrix $\left(M_{m j}\right)$ reduces to a scalar. Inverting these matrices costs nothing; this is a tremendous advantage when analyzing large-scale problems. Once the iteration vector is corrected, the new values of $\Delta Q, \Delta G$, and $\Delta J$, as well as the state variables $\sigma_{i j}, \Omega_{i j}, K, \varepsilon_{i j}$, and $\varepsilon_{i j}^{i}$, are subsequently updated.

(7) One of the most important parts of this iterative scheme is the convergence criteria. In order for the algorithm to be effective, realistic criteria should be utllized for terminating the iteration process. At the end of each iteration, the solution that has been obtained should be checked to see whether it has converged within preset tolerances or whether the iteration is diverging. If the convergence tolerances are too loose, inaccurate results are obtained; if the tolerances are too tight, excessive computational effort is wasted for needless accuracy. Three convergence criteria are incorporated into the proposed integration scheme. First, the iteration vector convergence criterion is defined as 


$$
\frac{\left\|u_{i}^{(k)}\right\|_{2}}{\left\|u_{i}^{(1)}\right\|_{2}} \leq \text { ETOLB }
$$

where ETOLB is a convergence tolerance set equal to 0.01 . The term $\left\|U_{i}^{(1)}\right\|_{2}$ is the two-norm of iteration vector in the first iteration. The $\left\|U_{i}^{(k)}\right\|_{2}$ is the two-norm of correction vector in the subsequent iterations. If the criterion is satisfied, the solution is obtained. There is no need to check other criterla. However, if it is not satisfied, two Cauchy stress convergence criteria need to be satisfied for the solution to converge. The first Cauchy stress convergence criterion is defined as

$$
\left\|\sigma_{i j}^{(k+1)}-\sigma_{i j}^{(k)}\right\|_{2}<\left\|\sigma_{i j}^{(k)}-\sigma_{i j}^{(k-1)}\right\|_{2}
$$

This is a criterion to prevent any unnecessary iterations. If it is satisfied, the second Cauchy sress convergence criterion is checked; it is defined as follows:

$$
\frac{\left\|\sigma_{i j}^{(k)}-\sigma_{i j}^{(k-1)}\right\|_{2}}{\left\|\sigma_{i j}^{(k-1)}\right\|_{2}}<\text { CTOL }
$$

where CTOL is set equal to 0.005 . This is a fairly tight tolerance.

The Cauchy stress was the only state variable selected for convergence checks because Cauchy stress is the only state variable needed at the global level. In contrast, the back and drag stresses have never been used at the global level.

NUMERICAL EXAMPLES AND COMPARISONS

To demonstrate the numerical behavior of the new integration scheme, it was coded into subroutine HYPELA (see Appendix $D$ ), which is written in FORTRAN 
and is interfaced with the MARC finite element program. The integral form of Walker's, Krieg, Swearengen, and Rohde's (KSR's) and Miller's constitutive models, as presented herein were incorporated into one subroutine. The subroutine is written in a very efficient and versatile way, as all three models are included and tied to one integration scheme. A HYPELA subroutine containing the differential form of Walker's model with a SAFE integration scheme was taken from Cassenti (1983b) and used primarily for comparison with the proposed UVAE integration scheme. Similar subroutines containing the differential form of KSR's and Miller's models with a SAFE scheme were also written and used in the same fashion; these are not provided in this report. For Walker's damage model presented in the section Coupled Continuum Damage and Viscoplastic Formulation, minor modifications that are needed can be made with relative ease to subroutine HYPELA, for both differential and integral forms. Hence, it is not reproduced in this work. All the analyses were performed on the Cray-XMP super computer at NASA Lewis Research Center. Comparions are based on the number of seconds of Central Processing Unit (CPU) time used.

Hysteresis Loop for Hastelloy-x Under Thermomechanical Loading at $1600^{\circ} \mathrm{F}$ An axisymmetric finite element model was used to simulate one quarter of a solid specimen made of Hastelloy-x metal, which is being used for jet engine combustor liners. The material constants of Hastelloy-x at $1600^{\circ} \mathrm{F}$ for Walker's, KSR's, and Miller's models are given in Cassenti (1983a). The cyclic response is governed by these parameters: strain rate $\dot{\varepsilon}=3.87 \times 10^{-3} \mathrm{sec}^{-1}$ and strain limit of $0.006 \mathrm{in.lin}$. One full cycle of load, consisting of three loading portions, was imposed as follows: portion 1 - loading, $0<\varepsilon \leq 0.006$; portion 2 - unloading, $0.006>\varepsilon \geq-0.006$; and portion 3 - loading. $-0.006<\varepsilon \leq 0.006$. For each model, three different total time steps, with 
equal step sizes, were specified (i.e., 20,40, and 80 time steps). Our purpose was to study the stability and accuracy of the algorithm as time-step size was increased.

Figure 3 shows the hysteresis loop of Walker's model for 80 time steps. Three different runs are plotted: SAFE integration with ERRORI $=0.0001$; SAFE integration with ERROR1 $=0.00001$; and proposed UVAE integration with ETOLB $=0.01$ and CTOL $=0.005$. The results are almost identical for all three runs. For 40 and 20 time steps, similar results were obtained, as shown in Figs. 4 and 5, respectively. However, comparison of CPU time (see Table I) indicates that the proposed UVAE scheme is more efficient computationally as the step size increases. Of course, greater accuracy is attained because of the iterative nature of the scheme, as compared to the SAFE scheme which is a noniterative type.

Figure 6 shows the results of the same three runs with KSR's model for 40 time steps. Results are again nearly identical. By comparing the CPU times summarized in Table I, conclusions simllar to those for Walker's model can be drawn. For Miller's model, the amounts of CPU time are quite different. Table I shows that the proposed UVAE scheme consumes 2.5 times more CPU time than does the SAFE scheme with ERRORI $=0.0001$ for the case of 80 time steps. However, as the number of time steps decreases or the size of time steps increases, the efficiency becomes comparable. Good accuracy is obtained for both schemes as shown in Fig. 7. Because this model has a very stiff region, the user has a tendency to be more conservative and specifies a tight tolerance for the SAFE scheme with ERRORI $=0.00001$; then CPU time is three to four times higher than with ERRORI $=0.0001$, as can be seen in Table I. The noniterative nature of the scheme lures the user to be conservative; however, this does not happen with the UVAE scheme since accuracy is always assured through iteration. 
Thermomechanical Fatigue Loops

Thermomechanical fatigue loops (TMF) are typical loading histories

experienced by Hastelloy-x material in jet engine combustor liners at elevated temperatures. Under such conditions, both mechanical load (in the form of imposed strain) and temperature are subjected to large changes as a function of time. In order to predict the life of combustor liners realistically, the analyst must have a precise knowledge of the stress-strain hysteresis behavior at the critical fatigue locations corresponding to the aforementioned loadings. The purpose of considering the TMF is twofold: the first is to demonstrate the capability of the proposed UVAE scheme in handling nonisothermal loadings, and the second is to assess the predictive capability of the Walker and KSR models, based on the proposed scheme, as compared to the experimental data reported in Cassenti $(1983 a, 1983 b)$.

Considered herein is the case of an open nonsymmetrical TMF cycle as shown in Fig. 8. The temperature varies sinusoidally from 950 to $1750^{\circ} \mathrm{F}$, with a temperature hold at $1750^{\circ} \mathrm{F}$ for 40 sec; the strain, which also varies sinusoldally, holds -0.43 percent for the same period. The total number of time steps used for all analyses was 56.

The results of using Walker's model for a SAFE scheme and using the UVAE integration scheme are presented in Figs. 9 and 10 along with the experimental results. Notice that the proposed scheme gives better results than the SAFE scheme (especially during steady-state conditions) when both are compared to the experimental results. The superiority of the proposed scheme's results are even more obvious in the KSR model results shown in Figs. 11 and 12 . Comparisons of CPU time for both schemes and both models are shown in Table II. The new scheme utilizes only 5 percent more CPU time for walker's model, and 
25 percent more for KSR's model, than does the SAFE scheme. However the new scheme's accuracy is undeniably better.

Annular Combustor Liner Test Rig

In this example, a large-scale analysis of a combustor liner was used to demonstrate the effectiveness of the UVAE scheme. The combustor liner is a cylindrical part of a gas turbine engine that was radiantly heated in the structural component response rig in the test liners. A photograph of the conventional test liner is shown in Fig. 13(a). The test liner, of sheetmetal seam-welded louver construction, is a nickel-base superalloy material, Hastelloy-x. The eight louvers are segments of an outer annulus of a combustor liner. The test liner has an inside diameter of approximately $50.8 \mathrm{~cm}(20 \mathrm{in.})$. Circumferential arrays of cooling holes cool the louver lips. Louvers 4 to 6 (see Fig. 13(b)) are the active test louvers, that is, the location where the heat flux to the test liner is considered to be relatively flat.

A typical engine's mission cycle (takeoff, cruise, landing, and taxi) of 3 to $4 \mathrm{hr}$ was simulated in $2.2 \mathrm{~min}$. This thermal cycle time is broken up into four segments (see Fig. 14): a 6-sec ramp up from minimum to maximum power; a $1-m i n$ hold time at maximum power; a $6-\mathrm{sec}$ ramp down from maximum to minimum power; and a l-min hold time at minimum power. Cyclic surface temperatures at two potentially critical fallure locations (the seam weld and the knuckle) on the liner of louver 5 are plotted in Fig. 15. These data were used in the heat transfer analysis, with MARC code, as boundary conditions (thermal loads). Details of this analysis can be found in Thompson and Tong (1986).

The output of the heat transfer analysis was used as input to the structural analysis program. A three-dimensional solid finite element model. of louver 5, consisting of 546 elements and 1274 nodes, is shown in Fig. 16 . 
Appropriate boundary conditions are assumed. Walker's model was used to perform the analysis for both the SAFE and the UVAE integration schemes. Because of the large amount of CPU time consumed, the results of only 10 time steps are presented. In Figs. 17 and 18 , hoop stress and strain at the seam weld and at the knuckle, respectively, are plotted. The results are in good agreement. Discrepancles are within 3 percent at the knuckle and 10 percent at the seam weld. However, a question arises about whether the SAFE scheme is accurate for a large-scale analys is with complex loading histories, since it is a subincremental noniterative approach. The error that occurs in each time step of a large-scale analysis may be sizable and cumulative. Because of the iterative approach of the proposed UVAE scheme, error is not accumulated. Comparison of CPU times shows that the UVAE scheme $(271 \mathrm{sec}$ ) has an 8-percent advantage over the SAFE scheme $(292 \mathrm{sec})$ when only 10 time-step increments are used.

Continuum Damage Behavior During Creep Rupture Test

In the section Coupled Continuum Damage and Viscoplastic Formulation, a damage model was incorporated into Walker's viscoplastic model in both differential and integral forms. The damage parameter $\psi$ was introduced. To test these models numerically, subroutine HYPELA was slightly modified. The finite element model is the same as for the Hastelloy-x hysteresis loop. It is first loaded to stress, which saturates at a value of 7500 psi throughout the analysis. The values of $A$ and $r$ were chosen as $6.20819891 \times 10^{-26}$ and 5.4 , respectively, to provide verification of the numerical scheme. The damage parameter $\psi$ was initially set equal to 1 and diminished toward zero, as shown in Fig. 19. No numerical difficulty was encountered. However, for the SAFE scheme, a breakdown occurred at $\psi=0.58$, even though a very small time step was specified. At creep rupture the strain was 0.0058 , and the rupture time 
was $3300 \mathrm{sec}$ (see Fig. 20). This example demonstrated that the proposed UVAE integration scheme possesses a tremendous advantage in the analysis of continuum damage mechanics.

SUMMARY OF RESULTS

A new uniformly valid asymptotic implicit integration algorithm for elasto-plastic-creep and unified viscoplastic theories, including continuum damage, is proposed and demonstrated through a user subroutine of the MARC commercial finite element code. Based on the results obtained, the following characteristics of the proposed algorithm can be stated:

1. The algorithm is iterative without a high computational cost.

2. The algorithm is stable for large time increments.

3. The results obtained are less user-dependent.

4. The algorithm is simple, easy to implement, and well suited for finite element applications.

5. Under complex loading histories, including multiaxial behaviors, the algorithm is accurate and efficient.

6. The algorithm was shown to possess a tremendous advantage in continuum damage mechanics.

7. The algorithm is suitable for large scale multiaxial problems. ACKNOWLEDGEMENTS

The authors would like to thank Mr. Mike Tong of Sverdrup Technology, Inc., Lewis Research Center Group, for his help in numerical examples. 


\section{(1) Differential Form}

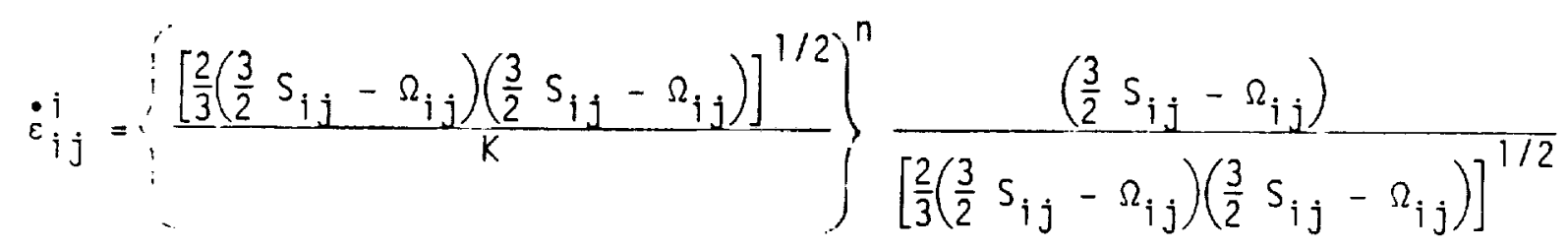

$$
\begin{aligned}
& \dot{\Omega}_{i j}=n_{2} \dot{\varepsilon}_{i j}^{i}-\left(\Omega_{i j}-\dot{\Omega}_{i j}\right) \dot{G}+\dot{\Omega}_{i j} \\
& K=K_{1}-K_{2} \exp \left(-n_{7} R\right)
\end{aligned}
$$

where

$$
\dot{G}=n_{3} \dot{R}+n_{6}\left(\frac{2}{3} \Omega_{i j} \Omega_{i j}\right)^{(m-1) / 2}
$$

(2) Uniformly Valid Asymptotic Expansion Form

$$
\begin{aligned}
\sigma_{i j}(t+\Delta t)=\frac{2}{3} \Omega_{i j}(t & +\Delta t)+\left(\lambda+\frac{2}{3} \mu\right) \delta_{i j} \varepsilon_{k k}(t+\Delta t) \\
+ & {\left[\sigma_{i j}(t)-\frac{2}{3} \Omega_{i j}(t)-\left(\lambda+\frac{2}{3} \mu\right) \delta_{i j} \varepsilon_{k k}(t)\right] \exp (-\Delta Q) } \\
& +\left(2 \mu \Delta \varepsilon_{i j}-\frac{2}{3} \mu \delta_{i j} \Delta \varepsilon_{k k}-\frac{2}{3} \Delta \Omega_{i j}\right)\left[\frac{1-\exp (-\Delta Q)}{\Delta Q}\right]
\end{aligned}
$$$$
\Omega_{i j}(t+\Delta t)=\stackrel{o}{\Omega}_{i j}(t+\Delta t)+\exp (-\Delta G)\left[\Omega_{i j}(t)-\stackrel{\circ}{\Omega}_{i j}(t)\right]+n_{2} \Delta \varepsilon_{i j}^{i}\left[\frac{1-\exp (-\Delta G)}{\Delta G}\right]
$$$$
K(t+\Delta t)=K_{1}(t+\Delta t)-K_{2}(t+\Delta t) \exp \left[-n_{7} R(t+\Delta t)\right]
$$

where

$$
\begin{gathered}
\Delta Q=\frac{3 \mu \Delta t}{K(t+\Delta t)} \dot{R}(t+\Delta t)^{1-(1 / n)} \\
\Delta G=\left\{n_{3} \dot{R}(t+\Delta t)+n_{6}\left[\frac{2}{3} \Omega_{1 k}(t+\Delta t) \Omega_{1 k}(t+\Delta t)\right]^{(m-1) / 2}\right.
\end{gathered}
$$


and $\lambda, \mu, \stackrel{\circ}{\Omega}_{i j}, n, m, n_{2}, n_{3}, n_{6}, n_{7}, k_{1}$, and $k_{2}$ are material constants and depend on temperature. 
(1) Differential Form

$$
\dot{\varepsilon}_{i j}^{i}=\left\{\frac{\left[\frac{2}{3}\left(\frac{3}{2} s_{i j}-\Omega_{i j}\right)\left(\frac{3}{2} s_{i j}-\Omega_{i j}\right)\right]^{1 / 2}}{k}\right\}^{n} \frac{\left(\frac{3}{2} s_{i j}-\Omega_{i j}\right)}{\left[\frac{2}{3}\left(\frac{3}{2} s_{i j}-\Omega_{i j}\right)\left(\frac{3}{2} s_{i j}-\Omega_{i j}\right)\right]^{1 / 2}}
$$

$$
\begin{gathered}
\dot{\Omega}_{i j}=A_{1} \dot{\varepsilon}_{i j}^{i}-A_{2} \Omega_{i j}\left(\frac{2}{3} \Omega_{p q} \Omega_{p q}\right)^{1 / 2}\left[\exp \left(A_{3} \frac{2}{3} \Omega_{p q} \Omega_{p q}\right)-1\right] \\
K=K_{0}
\end{gathered}
$$

(2) Uniformly Valid Asymptotic Expansion Form

$$
\begin{aligned}
& \sigma_{i j}(t+\Delta t)=\frac{2}{3} \Omega_{i j}(t+\Delta t)+\left(\lambda+\frac{2}{3} \mu\right) \delta_{i j} \varepsilon_{k k}(t+\Delta t) \\
&+\left[\sigma_{i j}(t)-\frac{2}{3} \Omega_{i j}(t)-\left(\lambda+\frac{2}{3} \mu\right) \delta_{i j} \varepsilon_{k k}(t)\right] \exp (-\Delta Q) \\
&+\left(2 \mu \Delta \varepsilon_{i j}-\frac{2}{3} \mu \delta_{i j} \Delta \varepsilon_{k k}-\frac{2}{3} \Delta \Omega_{i j}\right)\left[\frac{1-\exp (-\Delta Q)}{\Delta Q}\right] \\
& \Omega_{i j}(t+\Delta t)=\exp (-\Delta G) \Omega_{i j}(t)+A_{1} \Delta \varepsilon_{i j}\left[\frac{1-\exp (-\Delta G)}{\Delta G}\right] \\
& K=K_{0}
\end{aligned}
$$

where

$$
\begin{gathered}
\Delta Q=\frac{3 \mu \Delta t}{K(t+\Delta t)} \dot{R}(t+\Delta t) 1-(1 / n) \\
\Delta G=A_{2}\left(\frac{2}{3} \Omega_{p q} \Omega_{p q}\right)^{1 / 2}\left[\exp \left(A_{3} \frac{2}{3} \Omega_{p q} \Omega_{p q}\right)-1\right] \Delta t
\end{gathered}
$$

and $\lambda, \mu, n, A_{1}, A_{2}, A_{3}$, and $K_{0}$ are material constants which depend on temperature. 


\section{APPENDIX C}

\section{MILLER'S THEORY}

(1) Differential Form

$\dot{\varepsilon}_{i j}^{i}=B \theta^{\prime}\left\{\sinh \left[\frac{\frac{2}{3}\left(\frac{3}{2} s_{i j}-\Omega_{i j}\right)\left(\frac{3}{2} s_{i j}-\Omega_{i j}\right)}{k}\right]^{3 / 2}\right\}^{n}$

$$
\begin{gathered}
\times \frac{\left(\frac{3}{2} S_{i j}-\Omega_{i j}\right)}{\left[\frac{2}{3}\left(\frac{3}{2} S_{i j}-\Omega_{i j}\right)\left(\frac{3}{2} S_{i j}-\Omega_{i j}\right)\right]^{1 / 2}} \\
\dot{\Omega}_{i j}=H_{1} \dot{\varepsilon}_{i j}^{i}-H_{1} B \theta^{\prime}\left\{\sinh \left[A_{1}\left(\frac{2}{3} \Omega_{i j} \Omega_{i j}\right)^{1 / 2}\right]\right\}^{n} \frac{\Omega_{i j}}{\left(\frac{2}{3} \Omega_{i j} \Omega_{i j}\right)^{1 / 2}} \\
\dot{K}=H_{2} \dot{R}^{n}\left[C_{2}+\left(\frac{2}{3} \Omega_{i j} \Omega_{i j}\right)^{1 / 2}-\frac{A_{2}}{A_{1}} K^{3}\right]-H_{2} C_{2} B \theta^{\prime}\left[\sinh \left(A_{2} K^{3}\right)\right]^{n}
\end{gathered}
$$

where

$$
\begin{gathered}
\theta^{\prime}=\exp \left(-\frac{Q^{*}}{k T}\right) \quad \text { for } \quad T \geq 0.6 T_{m} \\
\theta^{\prime}=\exp \left(-\frac{Q^{\star}}{0.6 \mathrm{kT}}\right)\left[\ln \left(\frac{0.6 T_{m}}{T}\right)+1\right] \text { for } T<0.6 T_{m}
\end{gathered}
$$

(2) Uniformly Valid Asymptotic Expansion Form

$$
\begin{aligned}
& \sigma_{i j}(t+\Delta t)=\frac{2}{3} \Omega_{i j}(t+\Delta t)+\left(\lambda+\frac{2}{3} \mu\right) \delta_{i j} \varepsilon_{k k}(t+\Delta t) \\
&+\left[\sigma_{i j}(t)-\frac{2}{3} \Omega_{i j}(t)-\left(\lambda+\frac{2}{3} \mu\right) \delta_{i j} \varepsilon_{k k}(t)\right] \exp (-\Delta Q) \\
&+\left(2 \mu \Delta \varepsilon_{i j}-\frac{2}{3} \mu \delta_{i j} \Delta \varepsilon_{k k}-\frac{2}{3} \Delta \Omega_{i j}\right)\left[\frac{1-\exp (-\Delta Q)}{\Delta Q}\right] \\
& \Omega_{i j}(t+\Delta t)=\exp (-\Delta G) \Omega_{i j}(t)+H_{1} \Delta \varepsilon_{i j}^{i}\left[\frac{1-\exp (-\Delta G)}{\Delta G}\right] \\
& K(t+\Delta t)=K_{0}+\left[K(t)-K_{0}\right] \exp (-\Delta J)+H_{2} C_{2} \Delta R\left[\frac{1-\exp (-\Delta J)}{\Delta J}\right]
\end{aligned}
$$


where

$$
\begin{aligned}
& \Delta Q=\frac{3 \mu \dot{R}}{K} \frac{\Delta t}{\left[\sinh ^{-1}\left(\frac{\dot{R}}{B \theta^{1}}\right)^{1 / n}\right]^{2 / 3}} \\
& \Delta G=H_{j} B \theta^{\prime}\left\{\sinh \left[A_{1}\left(\frac{2}{3} \Omega_{i j} \Omega_{i j}\right)^{1 / 2}\right]\right\}^{n} \frac{\Delta t}{\left(\frac{2}{3} \Omega_{i j} \Omega_{i j}\right)^{1 / 2}} \\
& \Delta J=\frac{1}{\left[K(t+\Delta t)-K_{0}\right]}\left\{\left[H_{2} \frac{A_{2}}{A_{1}} K^{3}-H_{2}\left(\frac{2}{3} \Omega_{i j} \Omega_{i j}\right)^{1 / 2}\right]\right. \\
& \left.x \Delta R+H_{2} C_{2} B \theta \cdot\left[\sinh \left(A_{2} K^{3}\right)\right]^{n} \Delta t\right\rangle
\end{aligned}
$$




\section{APPENDIX D}

\section{SUBROUTINE HYPELA}

SUBROLTINE HYPELA (D, G , E , DE , S , TEMP , DTEMP , NGENS , N , NN , KC , YAT , NDI , INSHEAR)

$\mathrm{C}$
$\mathrm{C}$
$\mathrm{C}$
$\mathrm{C}$
$\mathrm{C}$
$\mathrm{C}$
$\mathrm{C}$
$\mathrm{C}$
$\mathrm{C}$
$\mathrm{C}$

A NEW VALID ASYMTOTIC INTEGRATION SCHEME FOR 3 VISCOPLASTIC MODELS

$$
\begin{array}{ll}
\text { MOD }=1, & \text { WALKER'S MODEL } \\
\text { MOD }=2, & \text { KSR'S MODEL } \\
\text { MOD }=3, & \text { MILLER'S MODEL }
\end{array}
$$

$\mathrm{C}$

DIYENSION D (NGENS, NGENS), G (NGENS), E (NGENS), DE (NGENS), S (NGENS)

DIMENSION TEMP (1), DTEMP (1)

DIMENSION SIGB (6), OMEGB (6), CB (6), SIGE (6), OMEGE (6), CE (6)

DIMENSION DC (6), DET (6), OMEGI (6)

DIMENSION DSIGIN (6), DS (6), AB(6)

DIMENSION $F(2,3), \operatorname{BUP}(3), \operatorname{DCTEMP}(6), \operatorname{T1SIG}(6), F Y(3,4)$

COMNON/AKEV / KEVIN

COMMON/FAR/DUM, INC

COMYON/CDC/DUMY (18), NCYCLE

C*****

$C * \ldots *$ SECOND INVARTANT FUNCTION

$\operatorname{SINV}(A, B, C, D, E, F)=(A * A+B * B+C * C+2 *(D * D+E * E+F * F)) * 2 . / 3$.

$\mathrm{C}$

C USERS SELECT THE VISCOPLASTIC MODEL

C

$$
\text { YOD }=1
$$

IF (YOD.LE. 3) GO TO 9

WRITE $(6,4711)$

471. FORMAT (' YODEL SELECTED IS INYALID - SOLUTION STOP') STOP

C****DETERMTNE IF PLANE STRESS, PLANE STRAIN, AXISYMMETRIC,OR 3-D

C.****KELTYP $=1$ FOR PLANE STRAIN AND AXISYMMTRIC PROBLEMS

$C * * * *$ KELTYP $=2$ FOR PLANE STRESS PROBLEM

$C * * * *$ KELTYP $=3$ FOR 3-D PROBLEM

9 IF (NDI . EQ . 3. AND . NSHEAR . EQ . 1) KELTYP=1

IF (NDI . EQ . 2 . AND . NSHEAR . EQ . 1) KELTYP $=2$

IF (NDI . EQ . 3 . AND . NSHEAR . EQ . 3) KELTYP=3

C.*** * SET UP CONSTANTS

MAXIT $=25$

NELPR $=1$

$\mathrm{IPR}=1$

NPRIN $=1$

SFTEMP $=936.2$

C... SET IP TOLERANCE

ETOLB - 0.01

CTOL $=0.005$

$\therefore \ldots \ldots$ PUT STRESSES AT BEGINNING OF MARC INCREMENT INTO SIGB ARRAY ACCORD

C......TO ELEMENT TYPE

G0 TO $(801,802,803)$, KELTYP

801 CONTINUE

$\operatorname{SICB}(1)=\mathrm{S}(1)$

$\operatorname{SIGB}(2)=S(2)$

$\operatorname{SICB}(3)=\mathrm{S}(3)$

$\operatorname{SIGB}(4)=\mathrm{S}(4)$

$\operatorname{SIGB}(5)=0$.

$\operatorname{SIGB}(6)=0$.

G0 TO 900

802 CONTINUE 


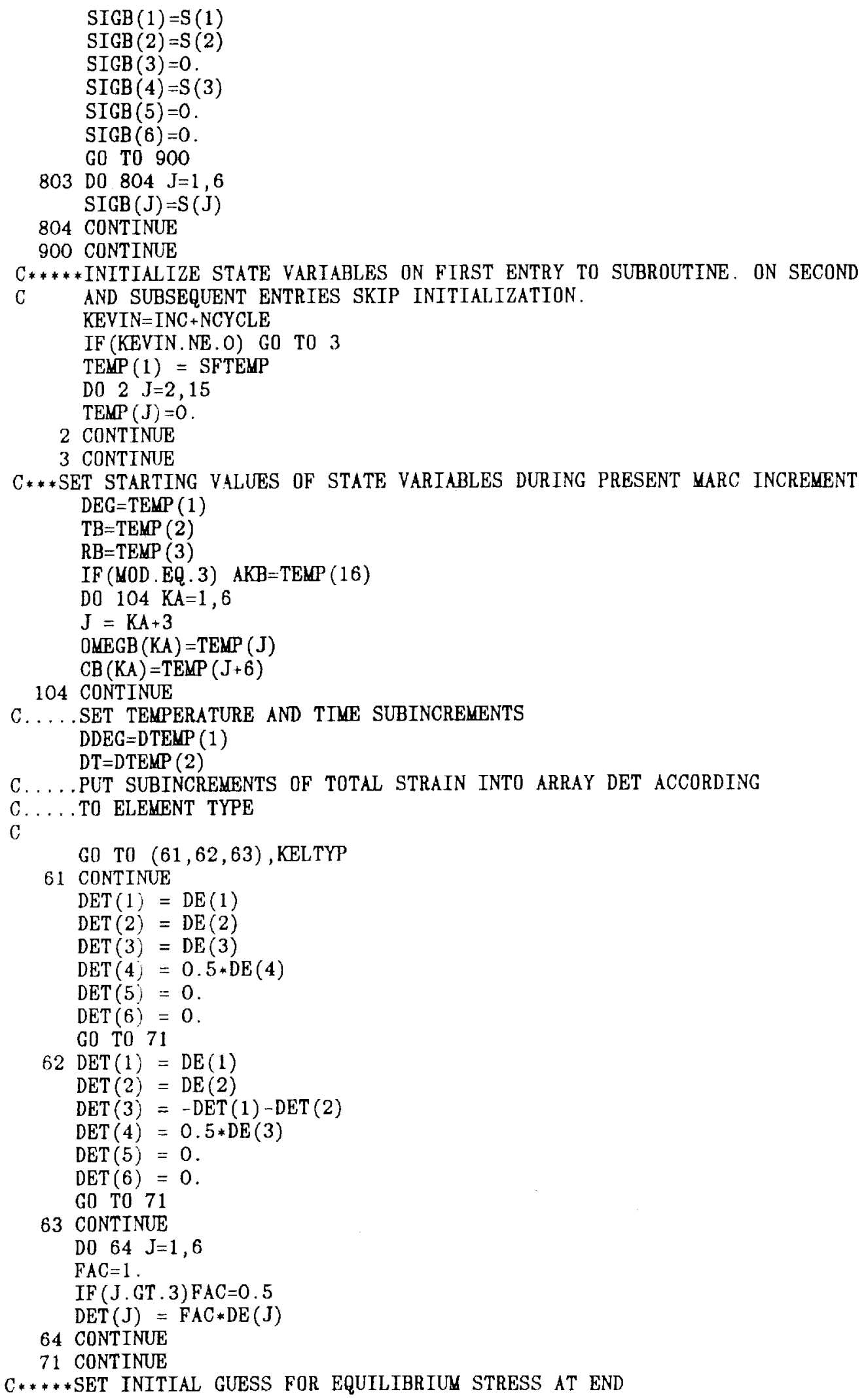




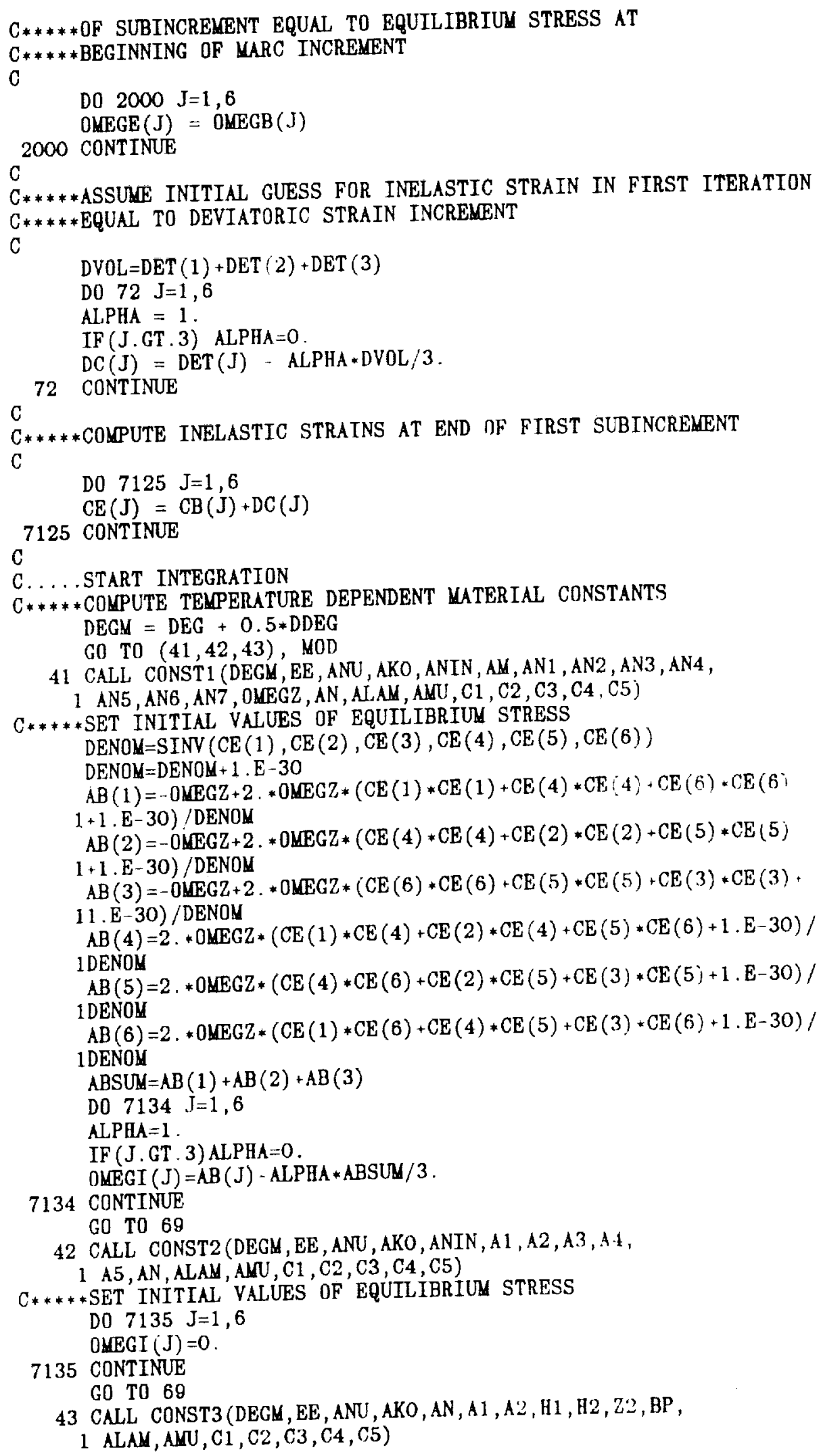




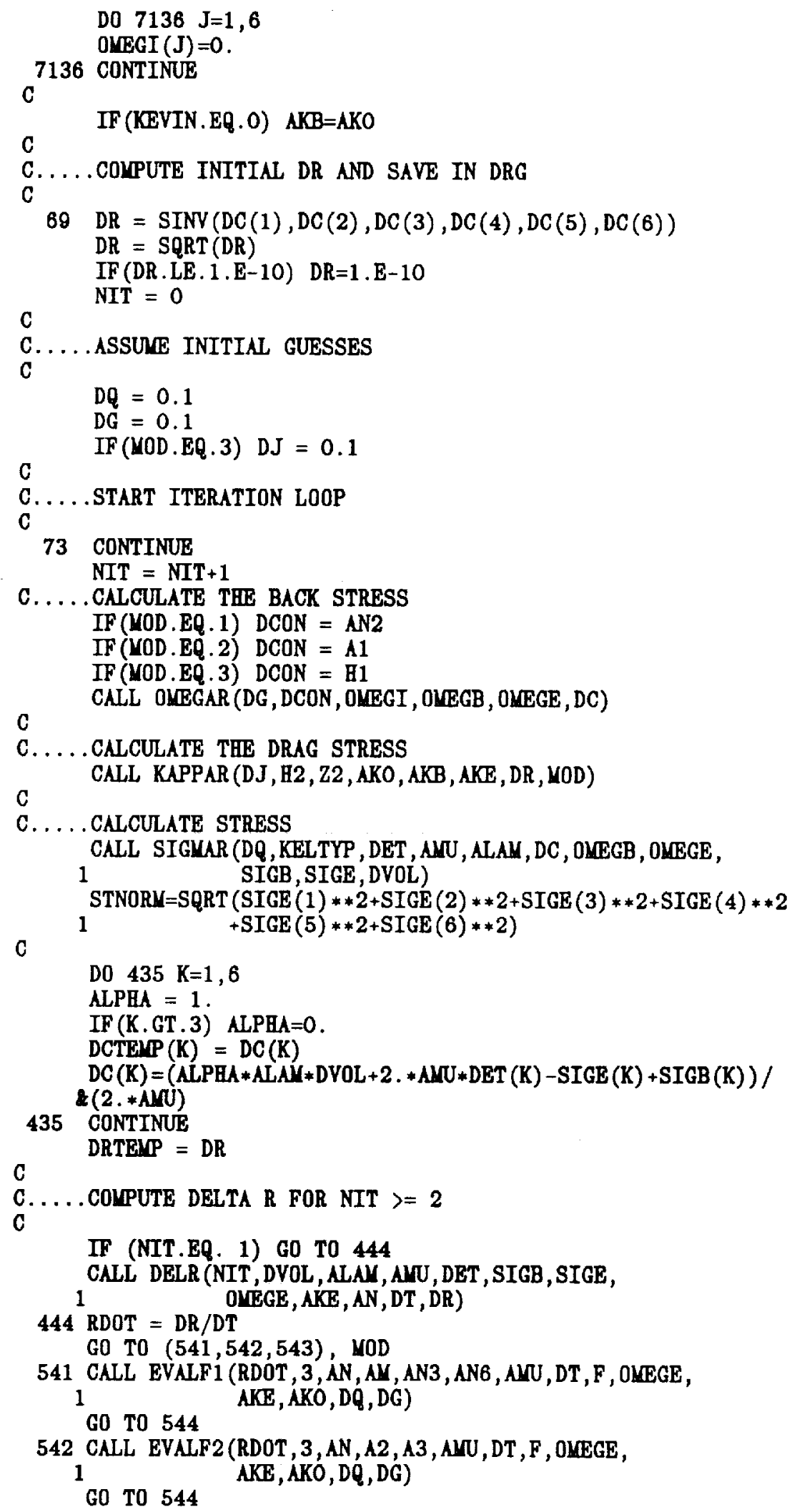




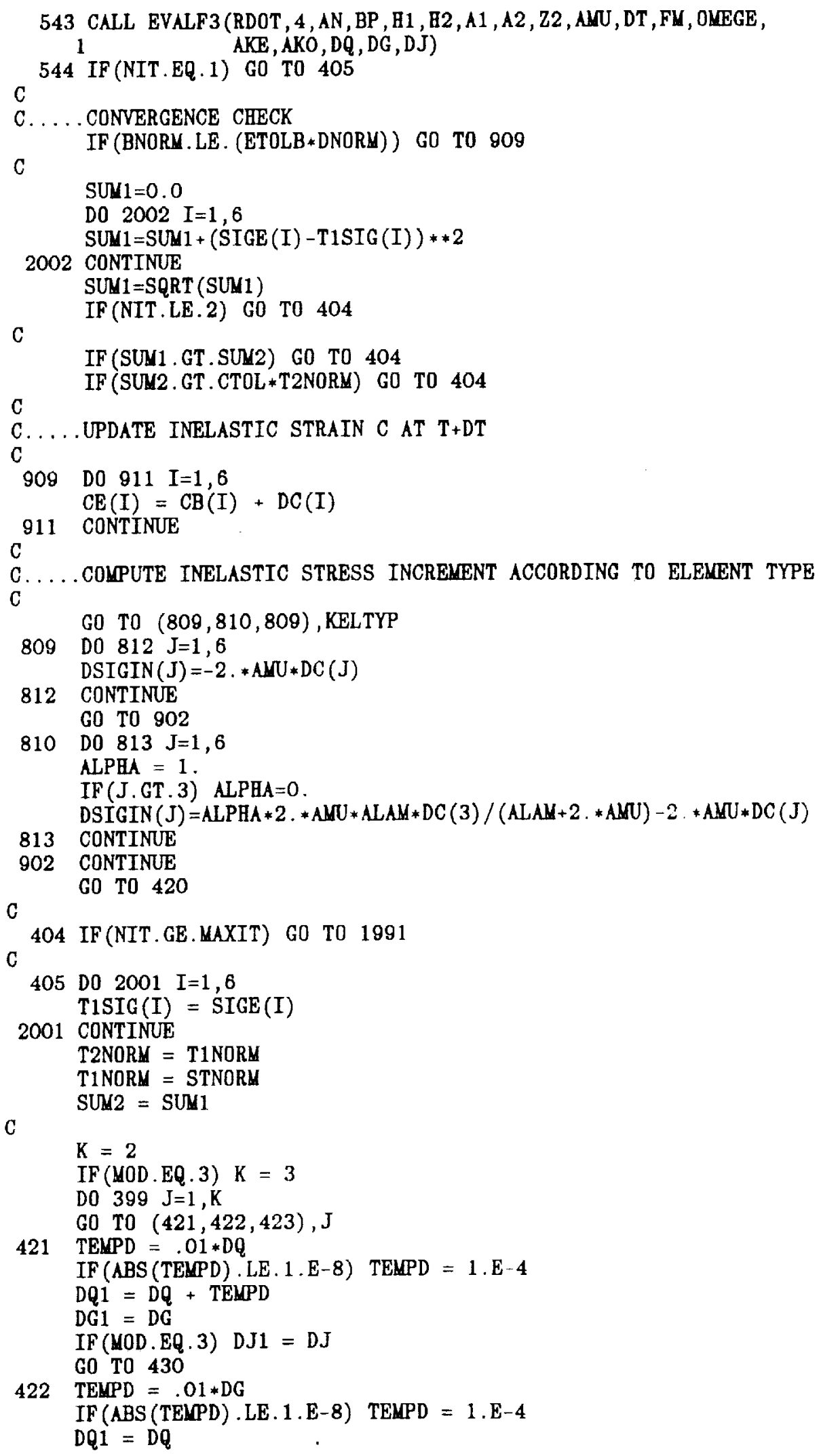




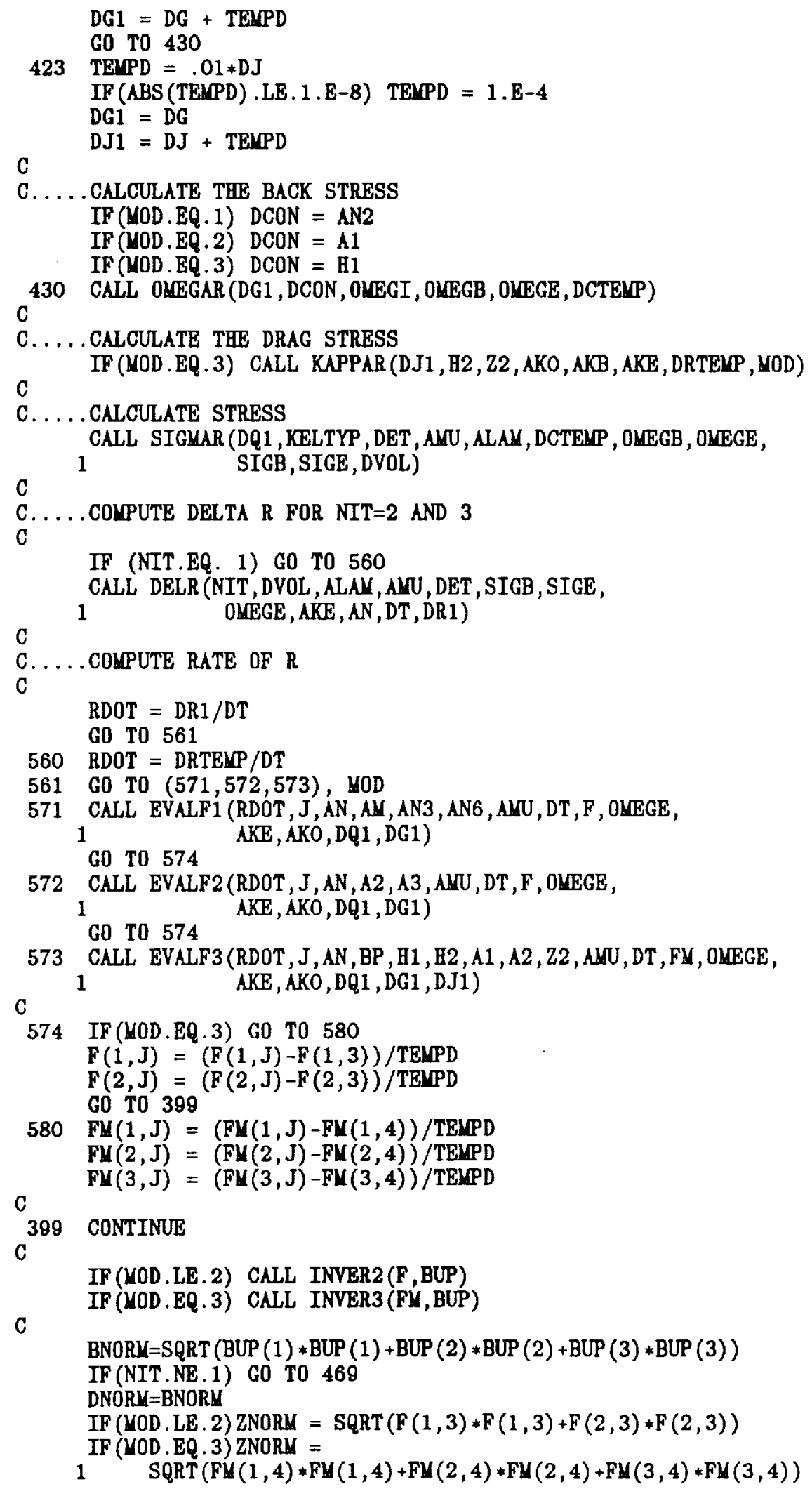




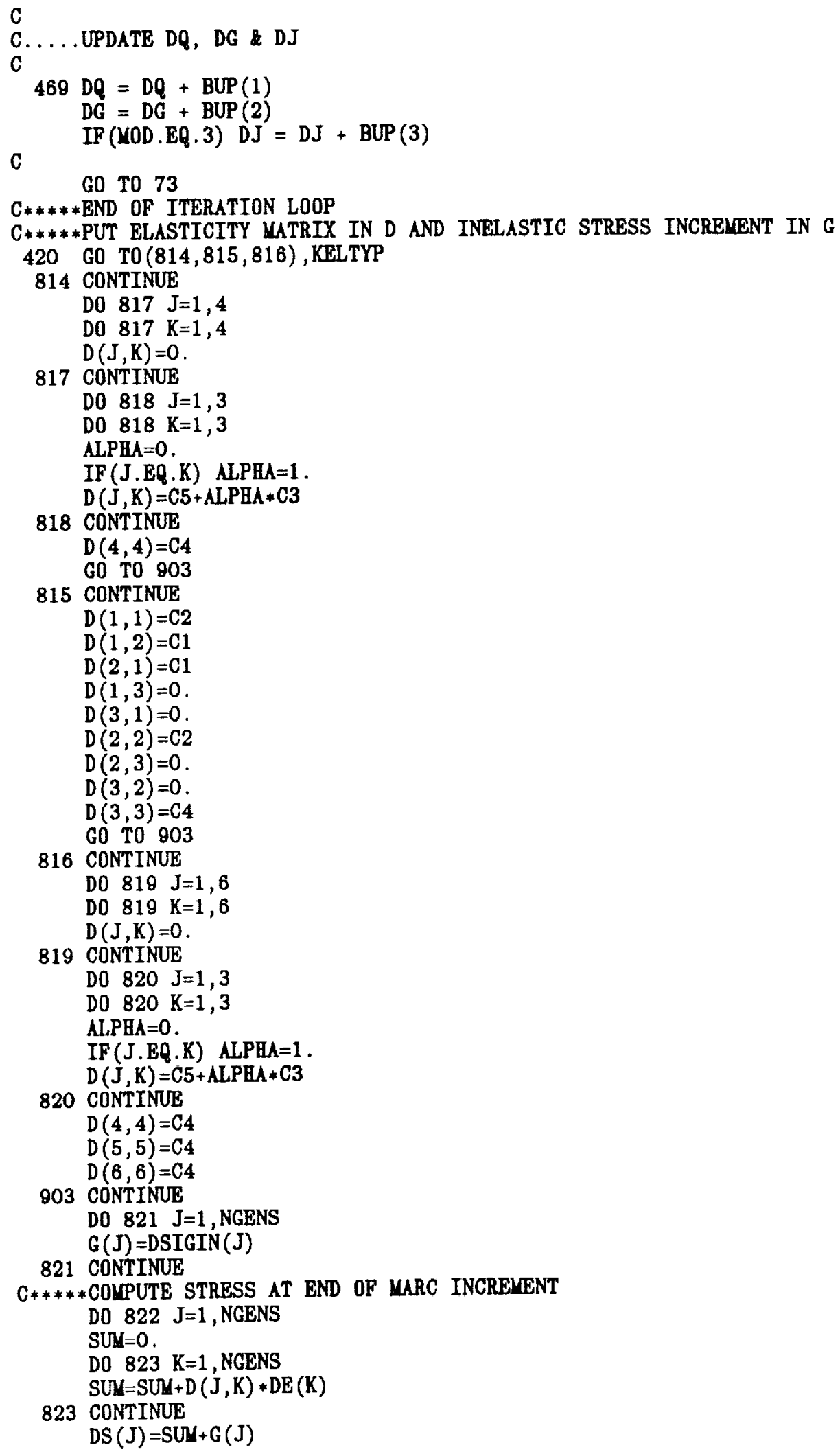




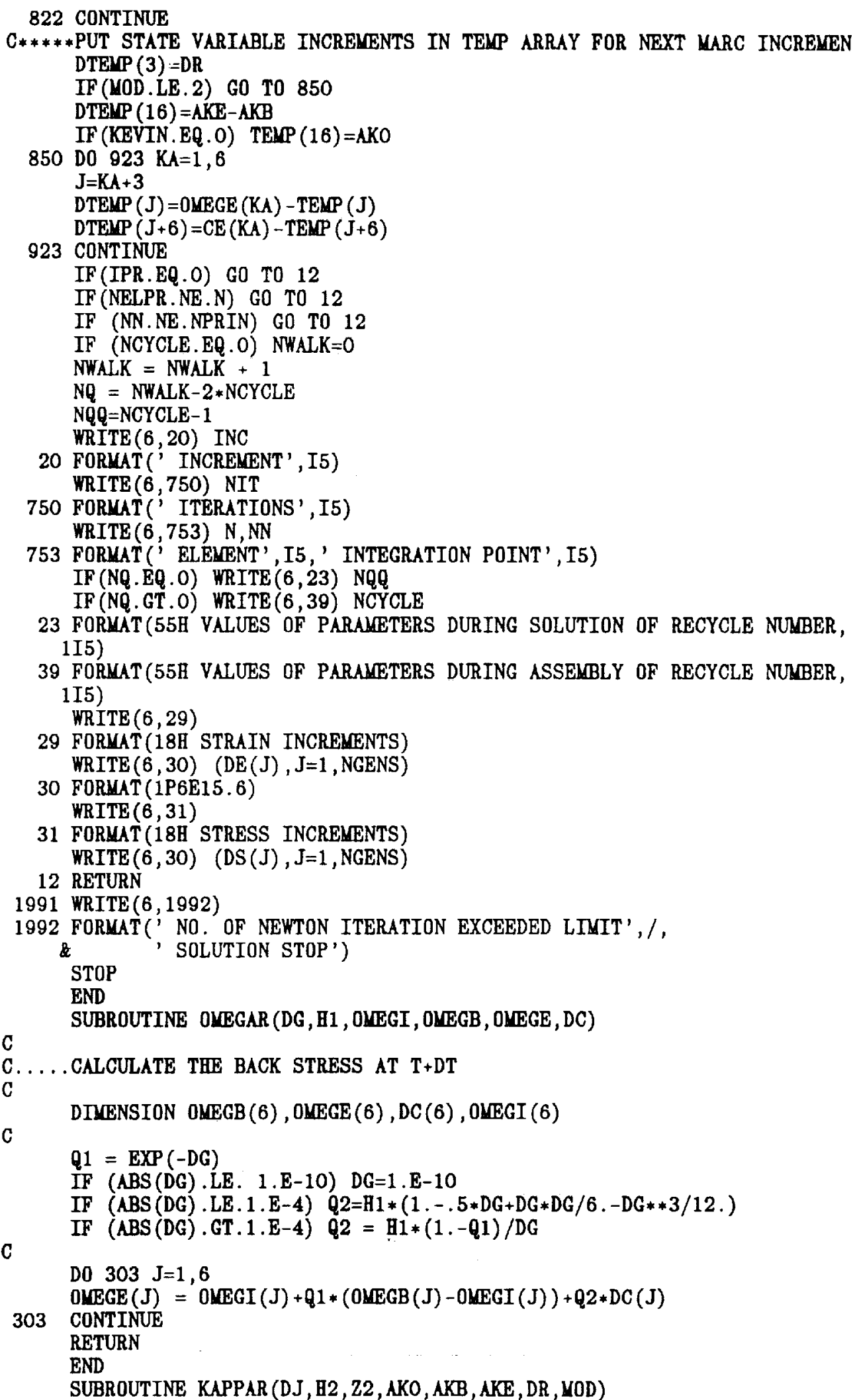

SUBROUTINE KAPPAR (DJ , H2 , Z2, AKO , AKB, AKE , DR , YOD) 


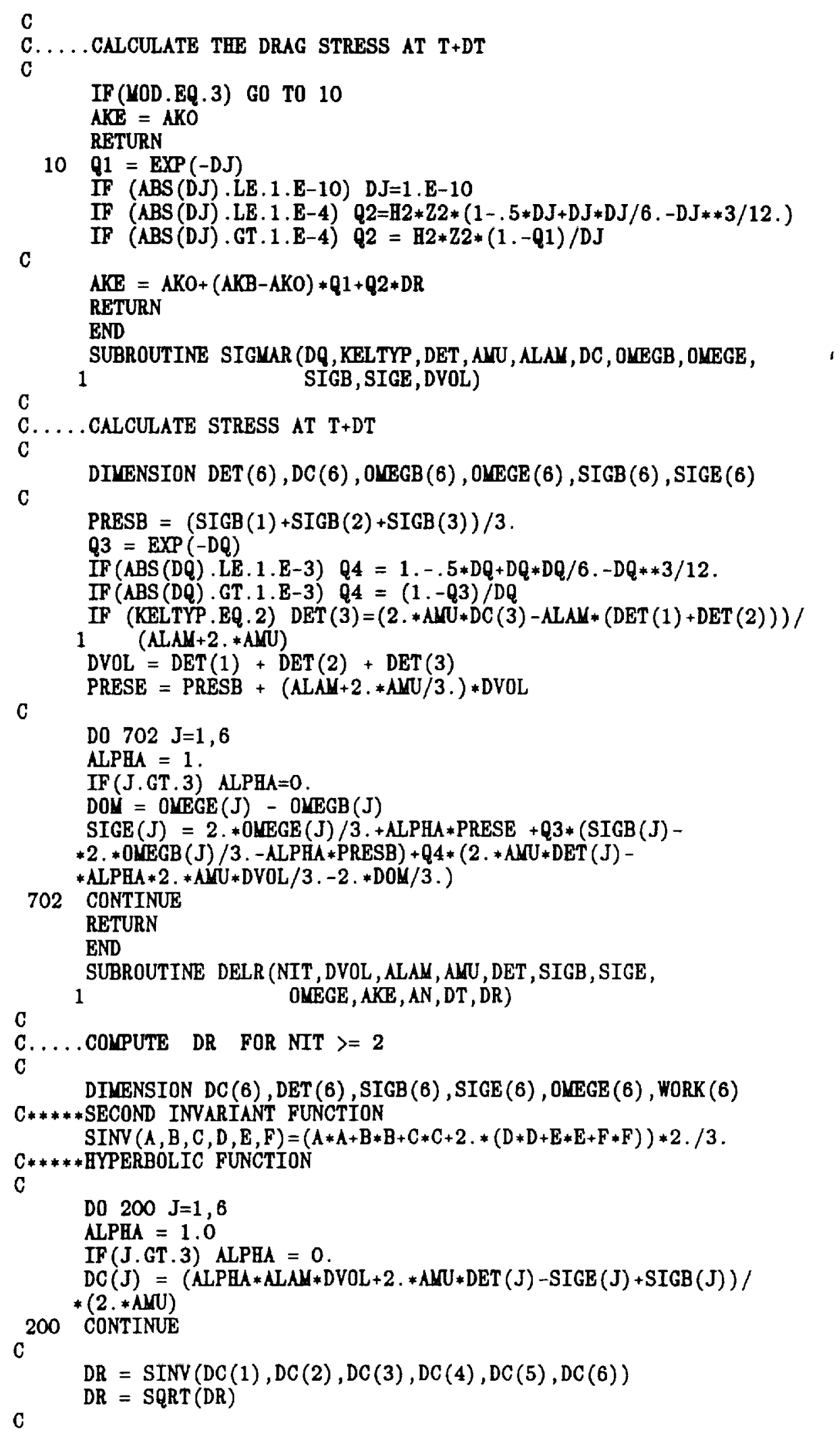




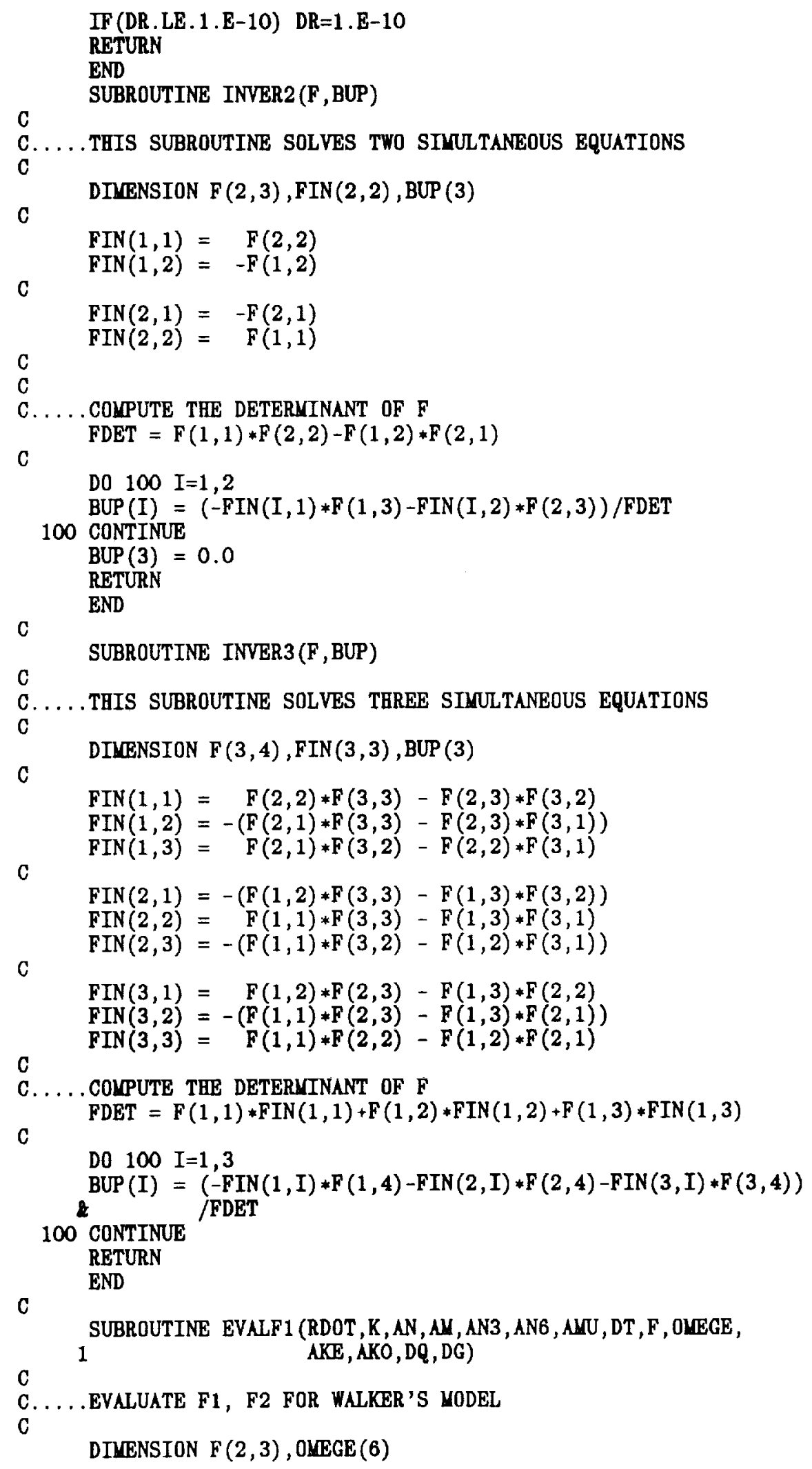




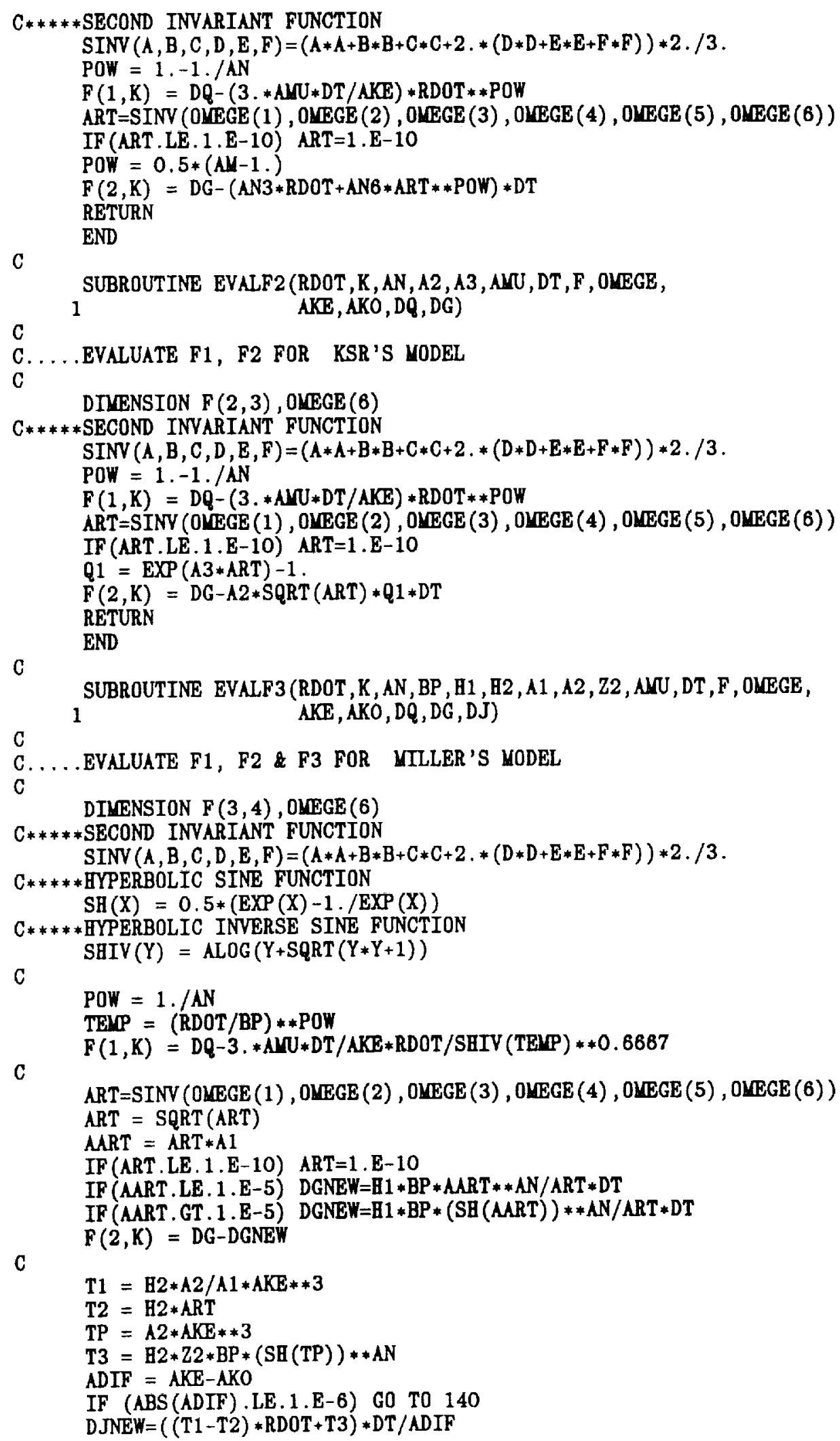


GO T0 150

140 DJNEW $=0$.

$150 F(3, K)=$ DJ-DJNEW

RETURN

END

C

SUBROUTINE CONST1 (DEG, EE , ANU, AKO , ANIN , AM , AN1 , AN2 , AN3 , AN4 , 1 AN5, AN6 , AN7 , OMEGZ, AN, ALAM , AMU , C1 , C2 , C3, C4, C5)

$\mathrm{C}$

C

C

THIS SUBROUTINE IS CALLED BY HYPELA TO CALCULATE ALL OF THE TEMPERATURE DEPENDENT YATERIAL CONSTANTS FOR WALKER'S MODEL

DINENSION TABT (6), EET (6), ANUT (6), AK1T (6), ANINT (6), ANT (6), AN1T (6)

DIMENSION AN2T (6), AN3T (6), AN4T (6), AN5T (6), AN6T (6), AN7T (6)

DIMENSION OMEGZT $(6)$

DATA TABT $/ 800 ., 1000,1200,1400,1600,1800 . /$

DATA EET/26.E6,24.E6, 24.E6,22.6E6, 18.6E6,13.2E6/

C DATA EET/26.E6 ,24.E6,23.4E6,21.8E6, 19.6E6, 16.8E6/

C DATA EET/26.E6,24.E6,23.4E6,22.5E6,21.6E6, 20.7E6/

DATA ANUT/0.322,0.328,0.334,0.339,0.345, $0.351 /$

DATA AK1T/50831.,75631.,95631.,251886.,91505.,59292./

DATA ANINT/.059, .059, .079, .244, .195,.223/

DATA AMT $/ 1.158,1.158,1.158,1.158,1.158,1.158 /$

DATA AN1T/0.,0.,0.,0.,0.,0./

DATA AN2T/30.E7,6.0E7, 1.5E7, 2.E7, 5.E6, 1.E6/

DATA AN3T $/ 8000 ., 1000 ., 781.2,1178.6,672.6,312.5 /$

DATA AN4T/0.,0.,0.,0.,0.,0./

DATA AN5T/0., 0., 0.,0.,0.,0./

DATA AN6T/0., 0.,0.,0.,8.977E-4, 2.733E-3/

DATA AN7T/0.,0.,0.,0.,0.,0./

DATA OMEGZT/0.,0.,-2000, ,-2000, ,-1434.,-1200./

$\mathrm{NTP}=6$

NTPY $1=$ NTP -1

$\mathrm{TDIF}=\mathrm{TABT}(2)-\mathrm{TABT}(1)$

$\mathrm{L} 1=\mathrm{DEG}$

$\mathrm{L} 2=\mathrm{TABT}(1)-\mathrm{TDTF}$

$\mathrm{L} 3=\mathrm{TDIF}$

$\mathrm{IT}=(\mathrm{L} 1-\mathrm{L} 2) / \mathrm{L} 3$

IF (IT . LT . 1) IT $=1$

IF (IT . GT . NTPM1) IT =NTPM1

FAC $=($ DEG - TABT $($ IT $)) / T D I F$

$\mathrm{EE}=(\operatorname{EET}(\mathrm{IT}+1)-\operatorname{EET}(\mathrm{IT})) * \mathrm{FAC}+\mathrm{EET}(\mathrm{IT})$

$A N U=(A N U T(I T+1)-A N U T(I T)) * F A C+A N U T(I T)$

$A K O=(A K 1 T(I T+1)-A K 1 T$ (IT ) $) * F A C+A K 1 T$ (IT)

ANIN $=($ ANINT $(I T+1)-$ ANINT (IT) $) *$ FAC+ANINT (IT)

$\mathrm{AM}=(\operatorname{ANT}(\mathrm{IT}+1)-\mathrm{AMT}(\mathrm{IT})) * \mathrm{FAC}+\mathrm{AMT}(\mathrm{IT})$

$A N 1=(A N 1 T(I T+1)-A N 1 T(I T)) * F A C+\Lambda N 1 T$ (IT)

$A N 2=(A N 2 T(I T+1)-A N 2 T(I T)) * F A C+A N 2 T(I T)$

AN3 $=($ AN3T $(I T+1)-A N 3 T$ (IT) $) * F A C+A N 3 T$ (IT)

AN4 $=($ AN4T $(I T+1)-\Lambda N 4 T$ (IT) $) * F A C+A N 4 T$ (IT)

AN5 $=($ AN5T $($ IT +1$)-$ AN5T (IT) $) *$ FAC + AN5T (IT)

AN6 $=($ AN6T $(\mathrm{IT}+1)-\mathrm{AN} 6 \mathrm{~T}$ (IT) $) *$ FAC + AN6T (IT)

AN7 $=($ AN7T $($ IT +1$)-$ AN7T (IT) $) *$ FAC + AN7T (IT)

ONEGZ $=($ OMEGZT (IT+1) -OMEGZT (IT) ) *FAC+ONEGZT (IT)

$\mathrm{AN}=1$. $/ \mathrm{ANIN}$

$\mathrm{ALAV}=\mathrm{EE} * \mathrm{ANU} /((1,-2 . * \mathrm{ANU}) *(1+\mathrm{ANU}))$

$\mathrm{ANU}=(1 .-2 . * \mathrm{ANU}) * \mathrm{ALAN} /(2 . * \mathrm{ANU})$

$C 1=2 . * A M U * A L A Y /(A L A Y+2 . * A M U)$

$\mathrm{C} 2=4$ * *AMU* $(\mathrm{ALAM}+\mathrm{AMU}) /(\mathrm{ALAM}+2 \cdot * \mathrm{AMU})$

$\mathrm{C} 3=2$. $* \mathrm{AHU}$ 
$\mathrm{C} 4=\mathrm{ANO}$

C5 $=\mathrm{ALAM}$

RETURN

END

$\mathrm{C}$

SUBROUTINE CONST2 (DEG, EE , ANU, AKO , ANIN , $A 1, A 2, \wedge 3, \wedge 4$, $1 \mathrm{~A} 5, \mathrm{AN}, \mathrm{ALAM}, \mathrm{AMU}, \mathrm{C1}, \mathrm{C2}, \mathrm{C3}, \mathrm{C4}, \mathrm{C5})$

C

THIS SUBROUTINE IS CALLED BY BYPELA TO CALCULATE ALL OF THE TEMPERATURE DEPENDENT MATERIAL CONSTANTS FOR KSR'S MODEL

DIMENSION TABT (6), EET (6), ANUT (6), AKIT (6), ANINT (6)

DINENSION A1T (6), A2T (6), A3T (6), $\mathrm{A} 4 \mathrm{~T}(6), \mathrm{A} 5 \mathrm{~T}(6)$

DATA TABT $/ 800 ., 1000 ., 1200 ., 1400,1600 ., 1800 . /$

DATA EET/26.E6, 24.E6, 24.E6, 22.6E6, 18.6E6, 13.2E6/

C

DATA EET $/ 26 . \mathrm{E} 6,24 . \mathrm{E} 6,23.4 \mathrm{E} 6,21.8 \mathrm{E} 6,19.6 \mathrm{E} 6,16.8 \mathrm{E} 6 /$

C

DATA EET/26.E6, 24.E6, 23.4E6, 22 .5E6, 21 .6E6, 20.7E6/

DATA ANUT/0.322,0.328,0.334,0.339,0.345,0.351/

DATA AK1T/50931.,75631 , 85631 .,251886.,91505.,59292./

DATA ANINT/.059,.059,.078,.244,.195,.223/

DATA A1T/3.E8, 6.E7, 1.5E7, 2.E7, 5.E6, 1.E6/

DATA A2T $/ .58, .00179, .68,1.54,14.96,243 . /$

DATA A3T $/ 1 . \mathrm{E}-12,1 . \mathrm{E}-12,1 . \mathrm{E}-12,1 . \mathrm{E}-12,1 . \mathrm{E}-12,1 . \mathrm{E}-12 /$

DATA A4T $/ 0 ., 0 ., 0 ., 0 ., 0 ., 0 . /$

DATA A5T $/ 0 ., 0 ., 0 ., 0 ., 0 ., 0.1$

NTP $=6$

NTPM $1=$ NTP -1

$\mathrm{TDIF}=\mathrm{TABT}(2)-\mathrm{TABT}(1)$

$\mathrm{L} 1=\mathrm{DEG}$

L2=TABT (1) -TDIF

L3 $3=$ TDIF

$\mathrm{IT}=(\mathrm{L} 1-\mathrm{L} 2) / \mathrm{L} 3$

IF (IT.LT. 1) IT $=1$

IF (IT . GT . NTPU1) IT=NTPM1

FAC $=($ DEG-TABT $($ IT $)) / T D I F$

$\mathrm{EE}=(\mathrm{EET}(\mathrm{IT}+1)-\mathrm{EET}(\mathrm{IT})) * \mathrm{FAC}+\mathrm{EET}(\mathrm{IT})$

ANU $=($ ANUT $(I T+1)-$ ANUT $($ IT $)) *$ FAC + ANUT (IT)

$\Lambda K O=(A K 1 T(I T+1)-A K 1 T(T T)) * F A C+A K 1 T(I T)$

ANIN $=($ ANINT $($ IT +1$)-$ ANINT $($ IT $)) *$ FAC + ANINT $($ IT $)$

$A 1=(A 1 T(I T+1)-A 1 T(I T)) * F A C+\Lambda 1 T(I T)$

$\Lambda 2=(\Lambda 2 T(I T+1)-A 2 T(I T)) * F A C+A 2 T(I T)$

$\Lambda 3=(\Lambda 3 T(I T+1)-\Lambda 3 T(I T)) * F A C+\Lambda 3 T(I T)$

$\Lambda 4=(\Lambda 4 T(I T+1)-\Lambda 4 T(I T)) * F \Lambda C+\Lambda 4 T(I T)$

$A 5=(\Lambda 5 T(I T+1)-A 5 T(I T)) * F A C+\Lambda 5 T(I T)$

$\mathrm{AN}=1$. $/ \mathrm{ANIN}$

$A L A Y=E E * A N U /((1 .-2 . * A N U) *(1 .+A N U))$

$A M U=(1 .-2 . * A N U) * A L A Y /(2 . * A N U)$

$\mathrm{C} 1=2 . * \mathrm{AMU} * \mathrm{ALAM} /(\mathrm{ALAM}+2 . * \mathrm{AMU})$

$\mathrm{C} 2=4$. *AMU* $(A L A M+A M U) /(A L A M+2, * A M U)$

$\mathrm{C3}=2$, *A.MU

$\mathrm{C} 4=\mathrm{AIU}$

C5=ALAY

RETURN

END

C

SUBROUTINE CONST3 (DEG , EE , ANU, AKO , AN , $A 1, A 2$, H1 , H2 , 22 , BP , 1 ALAM , AMU, C1 C2, C3, C4, C5)

C

THIS SUBROUTINE IS CALLED BY RYPELA TO CALCULATE ALL OF THE TEMPERATURE DEPENDENT MATERIAL CONSTANTS FOR MILLER'S MODEL 


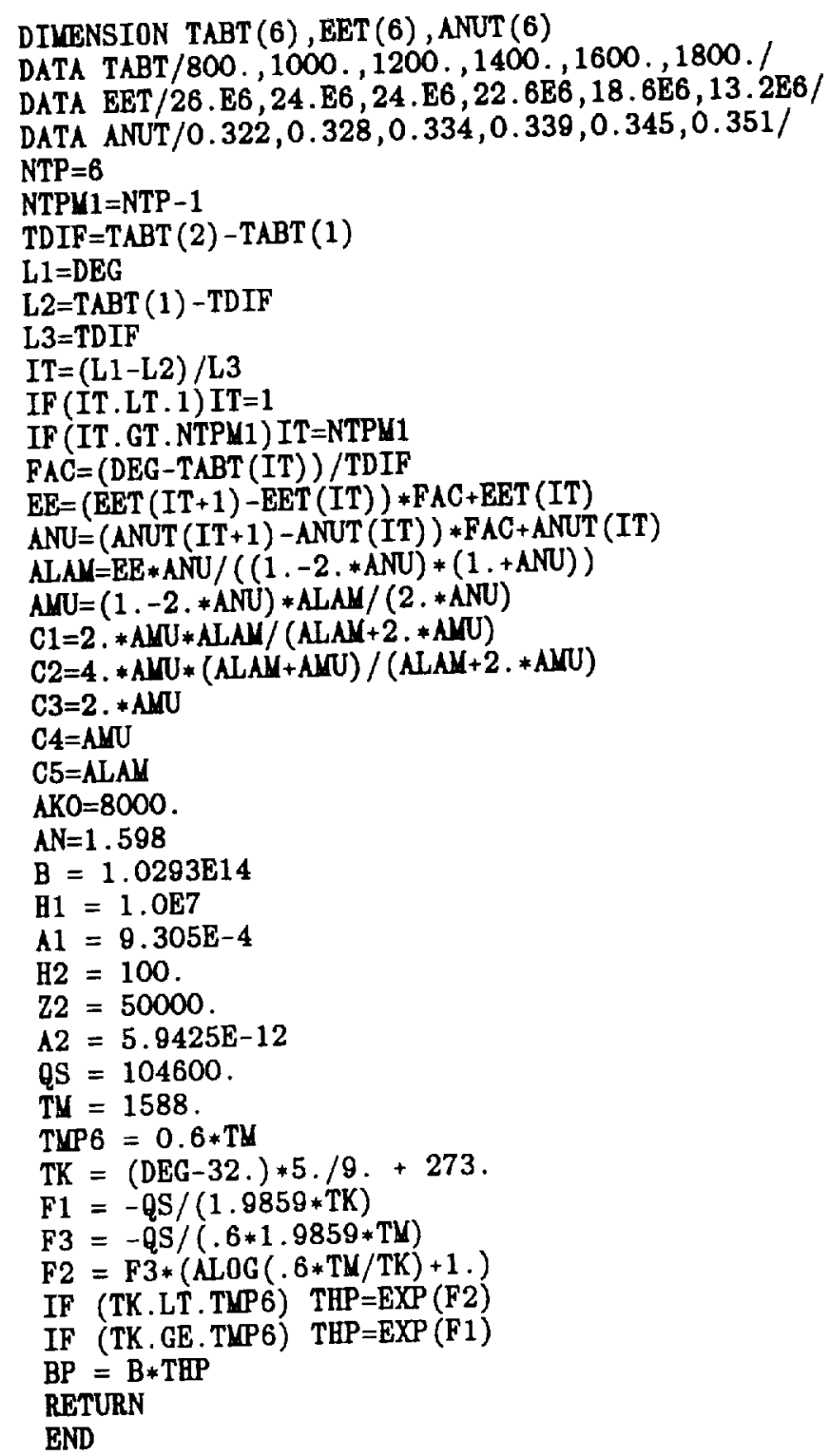


TABLE I. - COMPARISON OF CPU TIMES FOR WALKER'S, KSR'S, AND MILLER'S MODELS

$\left[\right.$ Temperature $=1600^{\circ} \mathrm{F}$ and strain rate $=3.87 \times 10^{-3}$ $\left.\sec ^{-1}.\right]$

\begin{tabular}{|c|c|c|c|}
\hline \multirow{3}{*}{$\begin{array}{l}\text { Number } \\
\text { of time } \\
\text { steps }\end{array}$} & \multicolumn{3}{|c|}{ CPU time, sec } \\
\hline & \multicolumn{2}{|c|}{ SAFE scheme } & UVAE scheme \\
\hline & $\begin{array}{l}\text { ERROR } 1 \\
1 \times 10^{-4}\end{array}$ & $\begin{array}{l}\text { ERRORI } \\
1 \times 10^{-5}\end{array}$ & $\begin{aligned} \text { ETOLB } & =1 \times 10^{-2} \\
\text { CTOL } & =5 \times 10^{-3}\end{aligned}$ \\
\hline \multicolumn{4}{|c|}{ Walker's model } \\
\hline $\begin{array}{l}80 \\
40 \\
20\end{array}$ & $\begin{array}{l}7.9 \\
5.8 \\
7.3\end{array}$ & $\begin{aligned} & 28.5 \\
+ & 28 \\
+ & 14\end{aligned}$ & $\begin{array}{l}7.4 \\
4 \\
2\end{array}$ \\
\hline \multicolumn{4}{|c|}{ KSR's mode I } \\
\hline $\begin{array}{l}80 \\
40 \\
20\end{array}$ & $\begin{array}{l}6 \\
4 \\
3\end{array}$ & $\begin{array}{r}17 \\
16 \\
+16\end{array}$ & $\begin{array}{l}7 \\
4 \\
2.4\end{array}$ \\
\hline \multicolumn{4}{|c|}{ Miller's model } \\
\hline $\begin{array}{l}80 \\
40 \\
20\end{array}$ & $\begin{array}{l}7 \\
5 \\
4\end{array}$ & $\begin{array}{r}22 \\
21 \\
+23\end{array}$ & $\begin{array}{l}17 \\
11 \\
4.5\end{array}$ \\
\hline
\end{tabular}

tConvergence is not satisfied. Fixed subincrement is employed.

TABLE II. - COMPARISON OF CPU TIME FOR 56 TIME STEPS

\begin{tabular}{|l|c|c|c|}
\hline \multirow{4}{*}{ Model } & \multicolumn{3}{|c|}{ CPU time, sec } \\
\cline { 2 - 4 } & \multicolumn{2}{|c|}{ SAFE scheme } & UVAE scheme \\
\cline { 2 - 4 } & ERRORI & ERRORI & ETOLB $=0.01$ \\
& $(0.0001)$ & $(0.00001)$ & CTOL $=0.005$ \\
\hline Walker's & 3.91 & 13.53 & 4.12 \\
KSR's & 3.14 & 7.30 & 4.05 \\
\hline
\end{tabular}




\section{REFERENCES}

Banthia, V.; and Mukherjee, S.: Improved Time Integration Scheme for Stiff Constitutive Models of Inelastic Deformation. DOE/ER-45055-5, 1982.

Bergan, P.G., et al.: Solution Techniques for Nonlinear Finite Element Problems. Int. J. Numer. Methods Eng., vol. 12, no. 11, 1978, pp. 1677-1696.

Cassenti, B.N.: Research and Development Program for the Development of Advanced Time-Temperature Dependent Constitutive Relationships. Vol. I Theoretical Discussion. NASA CR-168191-VOL-1, 1983.

Cassenti, B.N.: Research and Development Program for the Development of Advanced Time-Temperature Dependent Constitutive Relationships. Vol. II Programming Manual. NASA CR-168191-VOL-2, 1983.

Chang, J.P.: Finite Element Analysis of Metals at Elevated Temperature Using Unified Constitutive Theories. Ph.D. Thesis, Univ. of Akron, Akron, OH, 1985.

Fung, Y.C.: Foundations of Solid Mechanics. Prentice-Hall, Inc., 1965.

Gear, C.W.: The Automatic Integration of Ordinary Differential Equations," Commun. ACM, vol. 14, no. 3, 1971, pp. 176-179.

Kachanov, L.M.: Fundamentals of Fracture Mechanics, Nauka, Moscow, 1974 (in Russian). 
Kachanov, L.M.: On Creep Rupture Time. Izv. Akad. Nauk., SSSR, Otd. Tech. Nauk, No. 8, 1958 , pp. 26-31.

Kreig, R.D.; Swearengen, J.C.; and Rohde, R.W.: A Physically-Based Internal Variable Model for Rate-Dependent Plasticity. Inelastic Behavior of Pressure Vessel and Piping Components, T.Y. Chang and E. Krempl, eds., ASME, New York, 1978, pp. 15-28.

Lindholm, U.S., et al.: Constitutive Modeling for Isotropic Materials (HOST). (SWRI-06-7576/13, Southwest Research Inst., NASA Contract NAS3-23925) NASA CR-174718, 1985.

Lindholm, U.S., et al.: Constitutive Modeling for Isotropic Materials (HOST) (Second Annual Status Report). NASA CR-174980, 1985.

Malvern, L.E.: Introduction to the Mechanics of a Continuus Medium. Printice-Hall, Inc., 1969.

Meldelson, A.: Plasticity: Theory and Application. MacMillan Company, 1968.

Miller, A.K.; and Tanaka, T.G.: NONSS: A New Method for Integrating Unified Constitutive Equations Under Complex Histories. J. Eng. Mater. Technol., vol. 110, no. 3, July 1988, pp. 205-211.

Miller, A.K.: An Inelastic Constitutive Model for Monotonic, Cyclic, and Creep Deformation. J. Eng. Mater. Technol., vol. 98, no. 2, Apr. 1976, pp. 97-113. 
Miller, A.K.: A Unified Phenomenological Model for the Monotonic, Cyclic, and Creep Deformation of Strongly Work-Hardening Materials. Ph.D. Thesis, Stanford Univ., 1975.

Murakami, S.: Notion of Continuum Damage Mechanics and Its Application to Anisotropic Creep Damage Theory. J. Eng. Mater. Technol., vol. 105, no. 2, Apr. 1983, pp. 99-105.

Oden, J.T.: Finite Elements of Nonlinear Continua. McGraw-Hill Book Company, 1972.

Pugh, C.E., et al.: Currently Recommended Constitutive Equations for Inelastic Design Analysis of FFTF Components: ORNL-TM-3602, Sept. 1972.

Rabotnov, Y.N.: Creep Problems in Structural Members. North-Holland, 1969.

Snyder, M.D.; and Bathe, K.J.: A Solution Procedure for Thermo-Elastic-Plastic and Creep Problems. Nucl. Eng. Des., vol. 64, no. 1, 1981, pp. 49-80.

Stricklin, J.A.; Haisler, W.E.; and Von Reisemann, W.A.: Evaluation of Solution Procedures for Material and/or Geometrically Nonlinear Structural Analysis. AIAA J., vol. 11, no. 3, 1973, pp. 292-299. 
Thompson, R.L.; and Tong, M.T.: Unified Constitutive Materials Model Development and Evaluation for High-Temperature Structural Analysis Applications. ICAS, Congress, 15th, London, England, September 7-12, 1986, Proceedings, P. Santini and R. Staufenbiel, eds., AIAA, New York, 1986, vol. 2, pp. $1505 a-1505 s$.

Walker, K.P.: A Uniformly Valid Asymptotic Integration Algorithm for Unified Viscoplastic Constitutive Models. Advances in Inelastic Analysis, S. Nakazawa, K. William, and N. Rebelo, eds., ASME, New York, 1987, pp. 13-27.

Walker, K.P.: Representation of Hastelloy-X Behavior at Elevated Temperature with a Functional Theory of Viscoplasticity. Presented at the ASME/Pressure Vessels and Piping Century Two Emerging Technology Conference, San Francisco, CA, Aug. 1980.

Walker, K.P.: An Implicit Functional Theory of Viscoplasticity. Ph.D. Thesis, Rensselaer Polytechnic Inst., Troy, New York, 1976.

Walker, K.P.: Research and Development Program for Nonlinear Structural Modeling with Advanced Time-Temperature Dependent Constitutive Relationships. (PWA-5700-50, United Technologies Research Center, East Hartford, CT, NASA Contract NAS3-22055) NASA CR-165533, 1981. 


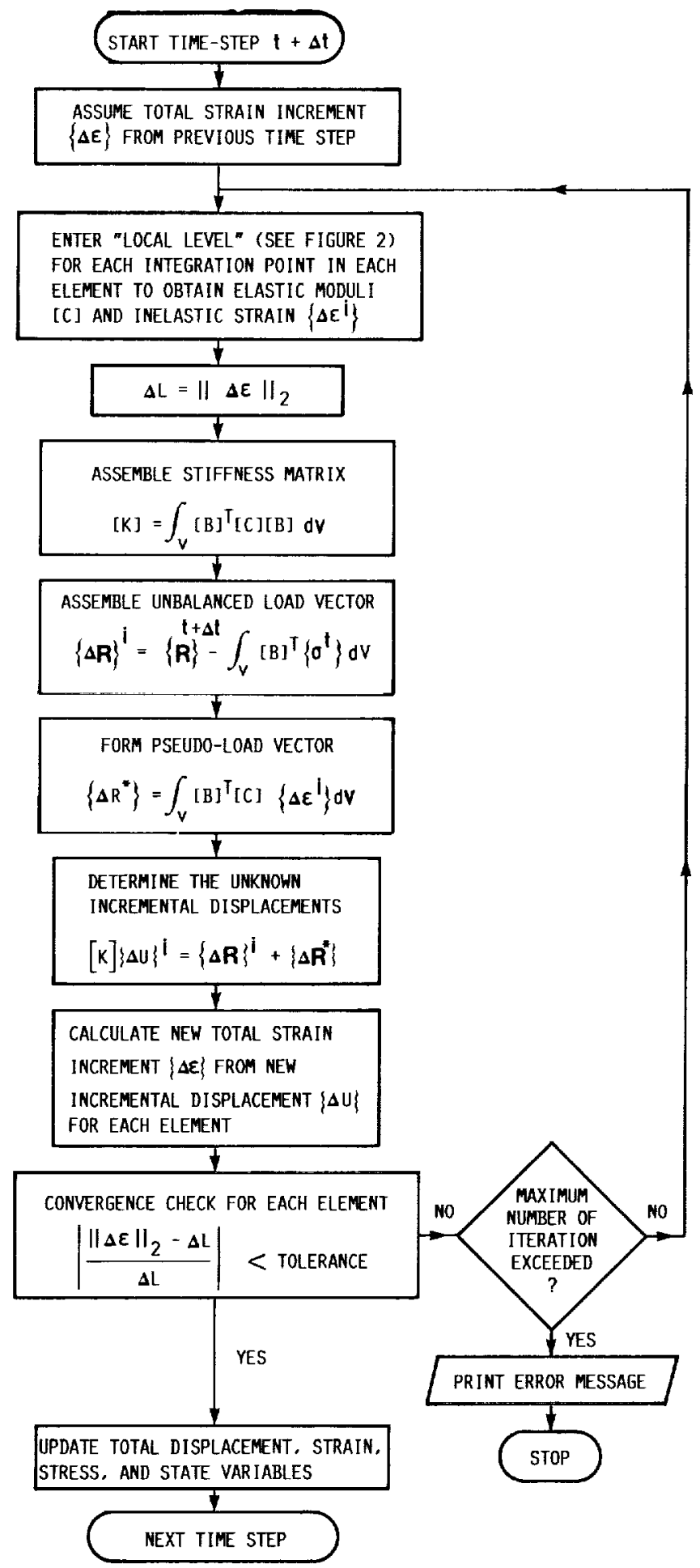

FIG, 1 FLOW CHART OF GLOBAL-INCREMENTAL ITERATION PROCEDURE IN NONLINEAR FINITE ELERENT AMALYSIS, BASED ON INITIAL STRAIN FETHOD. 


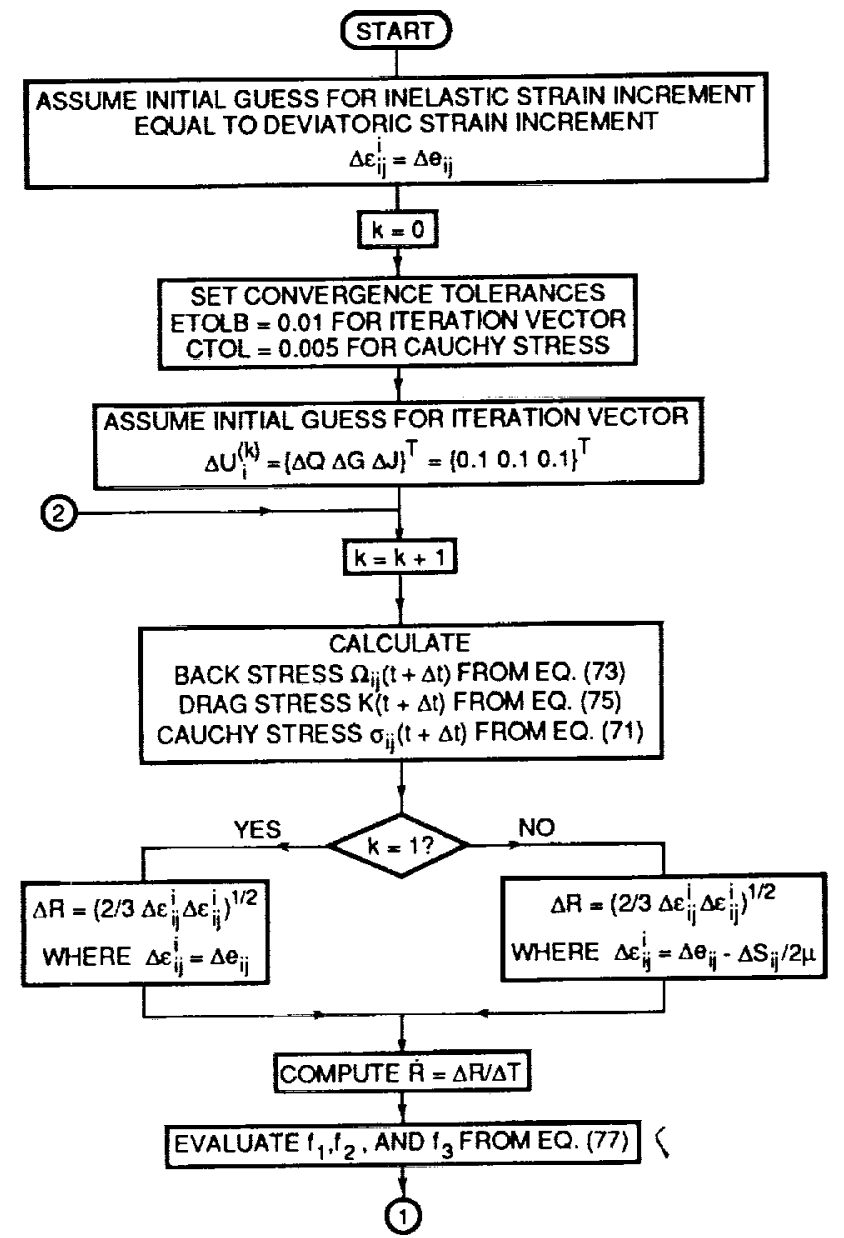

Figure 2. - Flow chan of new uniformly valid asymptotic integration scheme at local level.

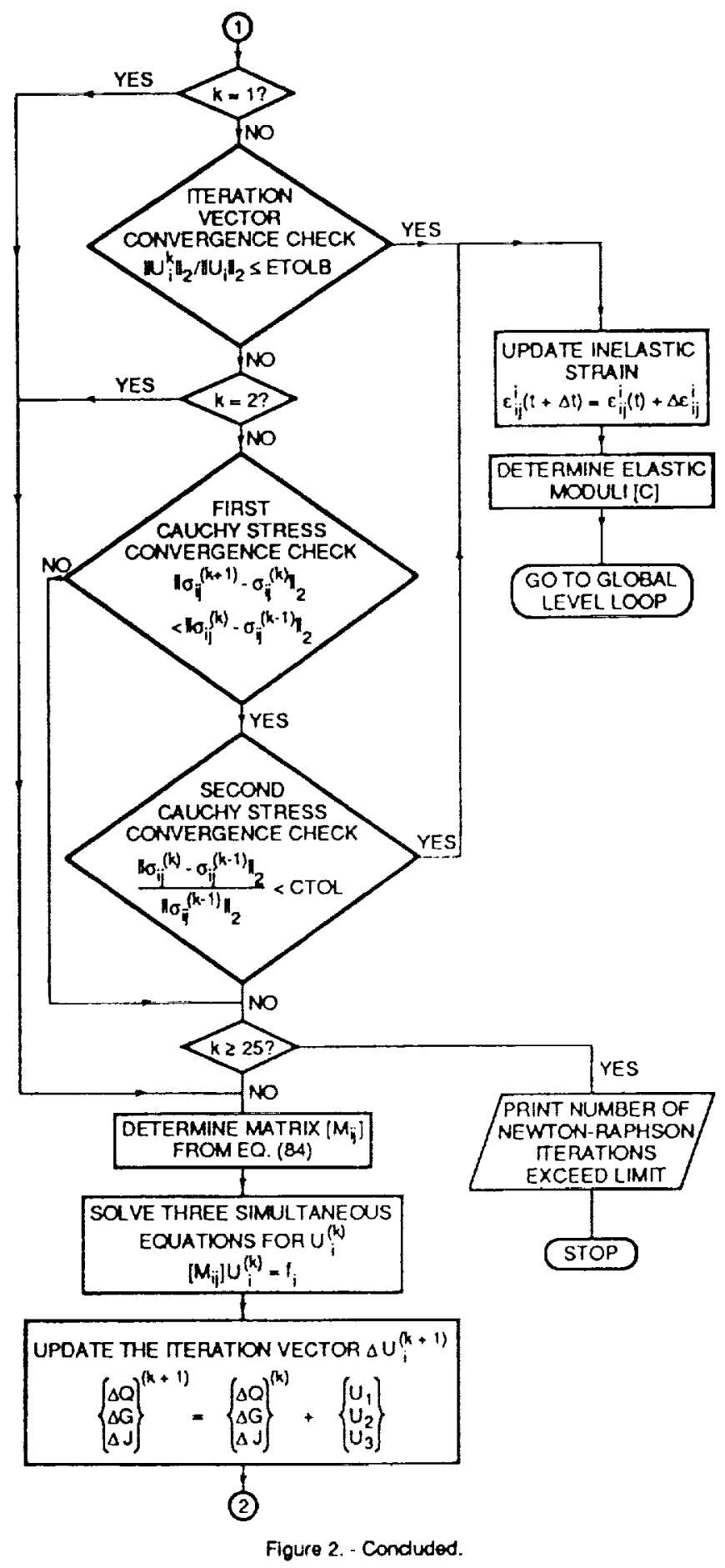




\section{INTEGRATION SCHEFE}

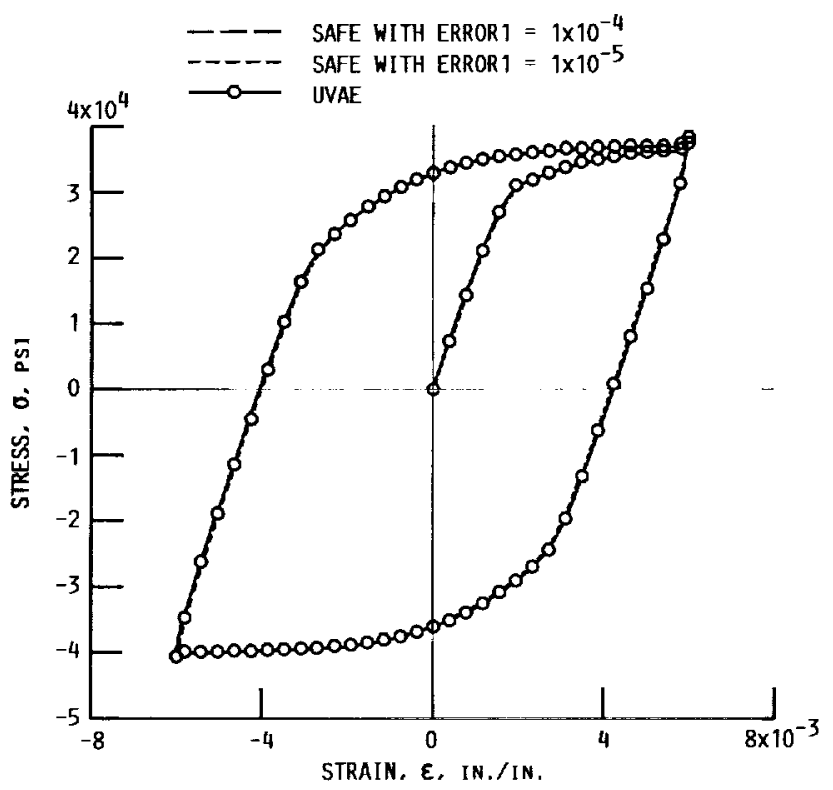

FIG. 3 HYSTERESIS LOOP PREDICTIONS OF WALKER'S MODEL FOR HASTELLOY-X; TEMPERATURE $=16000^{0}$; STRAIN RATE $=$ $3.87 \times 10^{-3} / \mathrm{SEC}$ : AND NUMBER OF TIME STEPS $=80$.

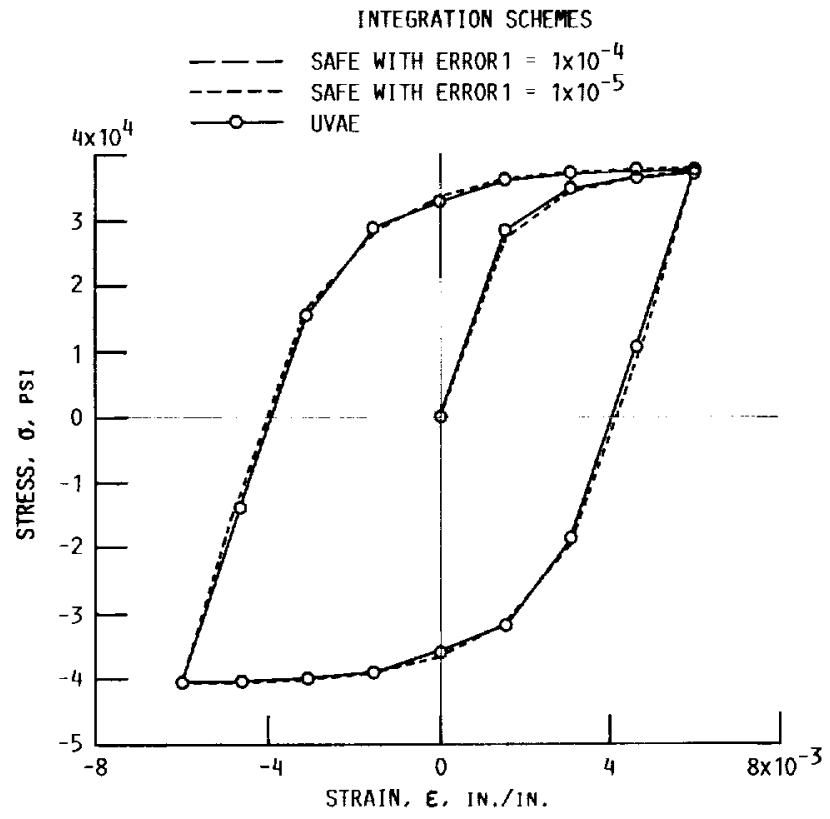

FIG, 5 HYSTERSIS LOOP PREDICTIONS OF WALKER'S MODEL FOR HASTELLOY-X; TEMPERATURE $=1600^{\circ} \mathrm{F}$; STRAIN RATE $=$ $3.87 \times 10^{-3} / \mathrm{SEC}$ : AND NUMBER OF TIHE STEPS $=20$.

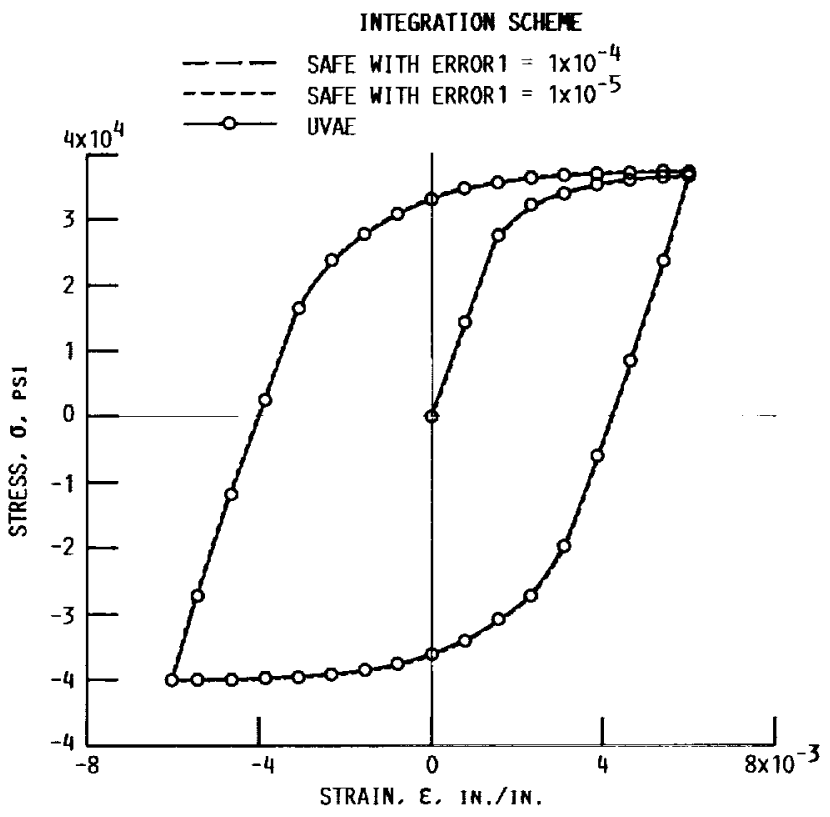

FIG. 4 HYSTERESIS LOOP PREDICTIONS OF WALKER'S MODEL FOR HASTELLOY- $X:$ TEMPERATURE $=1600^{\circ} \mathrm{F}:$ STRAIN RATE $=$ $3.87 \times 10^{-3} / \mathrm{sEC}$; NDD WUER OF TIRE STEPS $=40$.

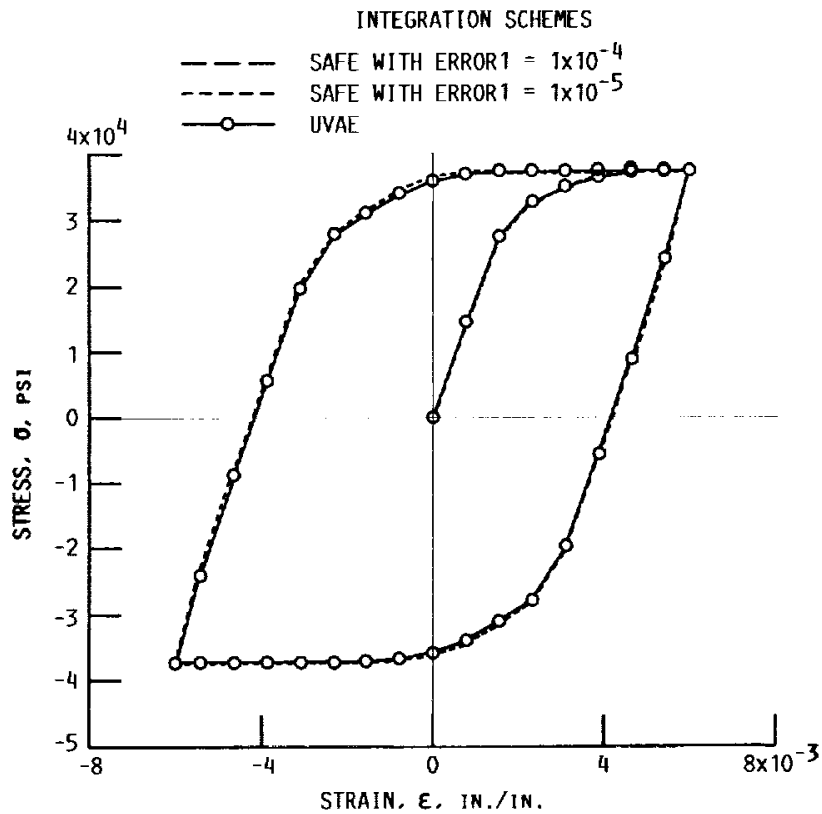

FIG. 6 HYSTERESIS LOOP PREDICTIONS OF KSR MODEL FOR HASTELLOY-X: TEMPERATURE $=1600^{\circ} \mathrm{F}$; STRAIN RATE $=$ $3.87 \times 10^{-3} / \mathrm{SEC}$; NUMBER OF TIFE STEPS $=40$. 


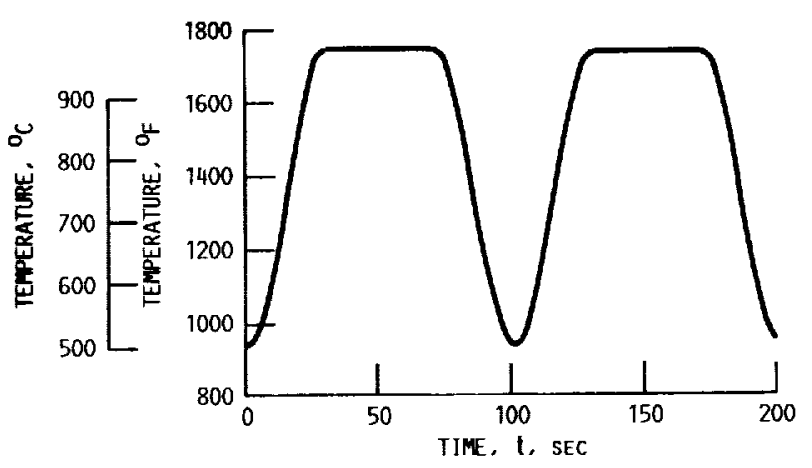

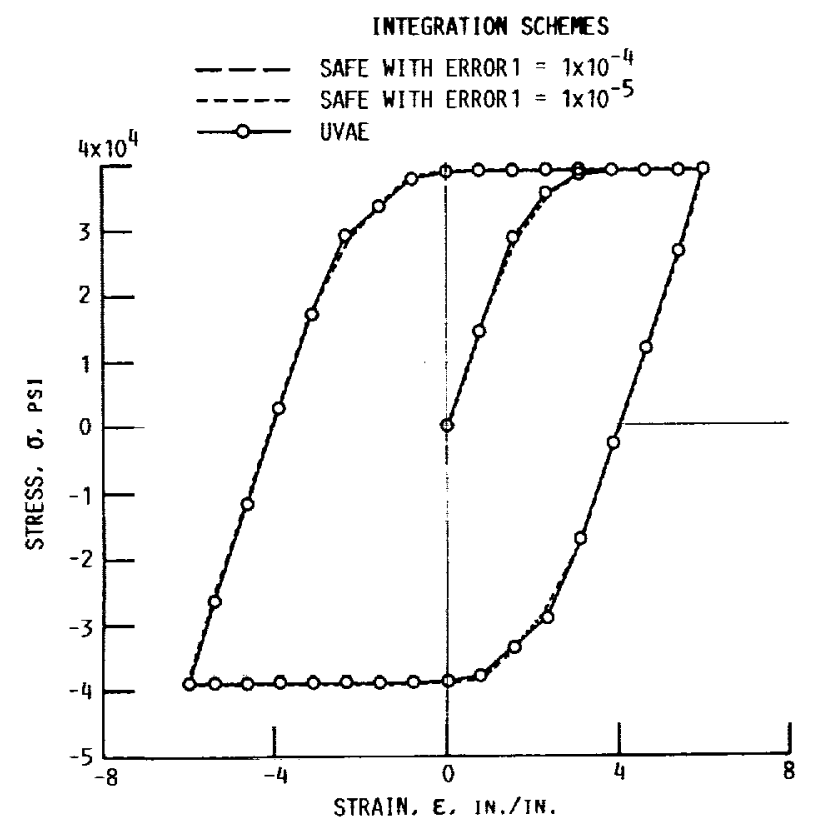

FIG. 7 HYSTERESIS LOOP PREDICTIONS OF MILLER'S MODEL FOR HASTELLOY $X$; TEMPERATURE $=1600^{\circ} \mathrm{F}$; STRAIN RATE $=$ $3.87 \times 10^{-3} / \mathrm{SEC}$; AND NUMBER OF TINE STEPS $=40$.
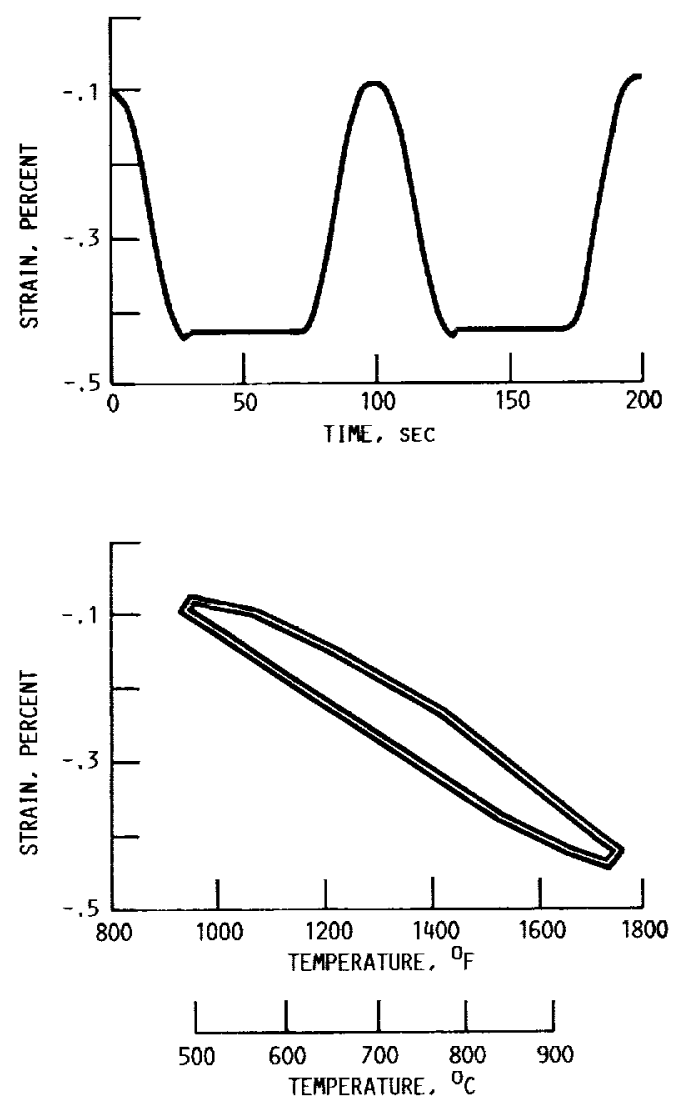

FIG. 8 OPEN NONSYMMETRICAL THERMOCHEMICAL FATIGUE LOADING CYCLE. 


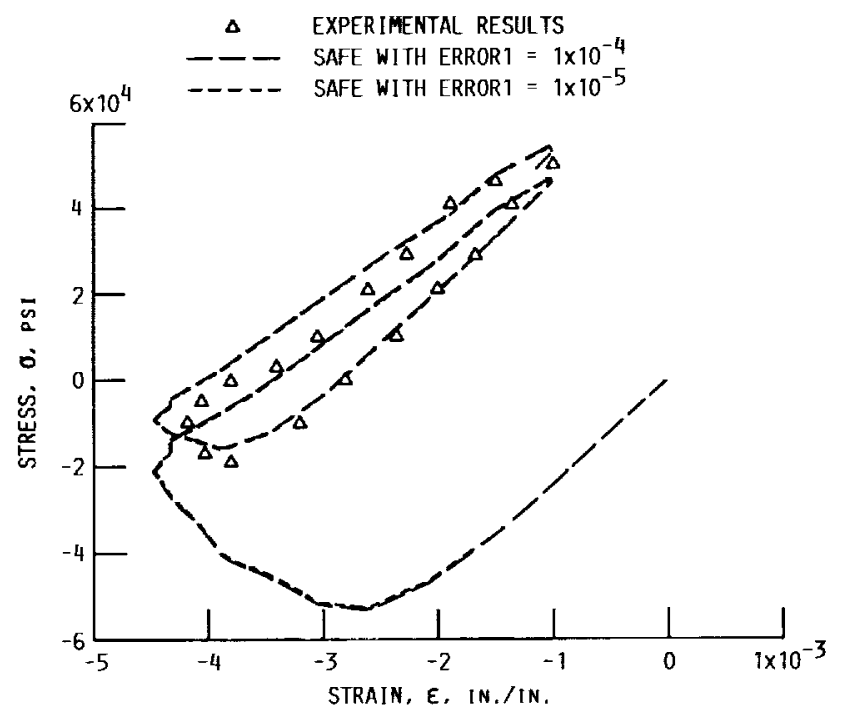

FIG. 9 THERMOMECHANICAL FATIGUE LOOP PREDICTIONS FROM WALKER'S DIFFERENTIAL FORM WITH SAFE INTEGRATION SCHEME.

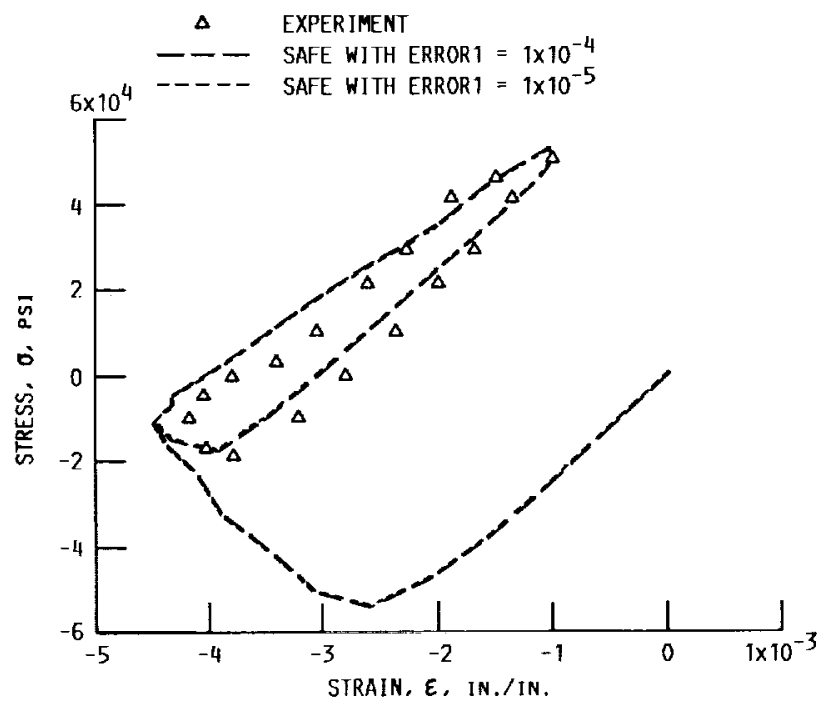

FIG. 11 THERMOMECHANICAL FATIGUE LOOP PREDICTIONS FROM KSR'S DIFFERENTIAL FORM WITH SAFE INTEGRATION SCHEME.

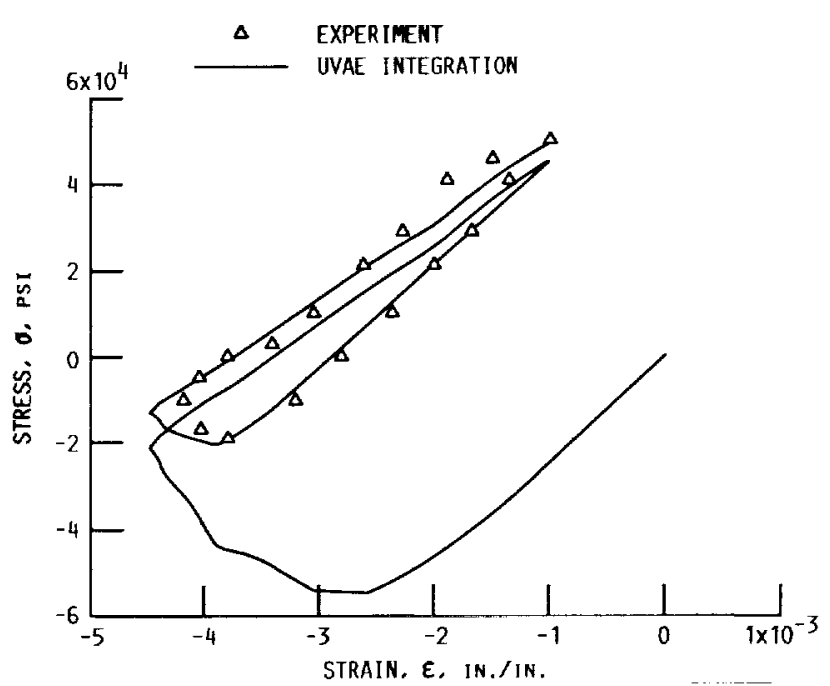

FIG. TO THERMOMECHANICAL FATIGUE LOOP PREDICTIONS FROM WALKER'S INTEGRAL FORM WITH THE PROPOSED UVAE INIEGRATION SCHEME.

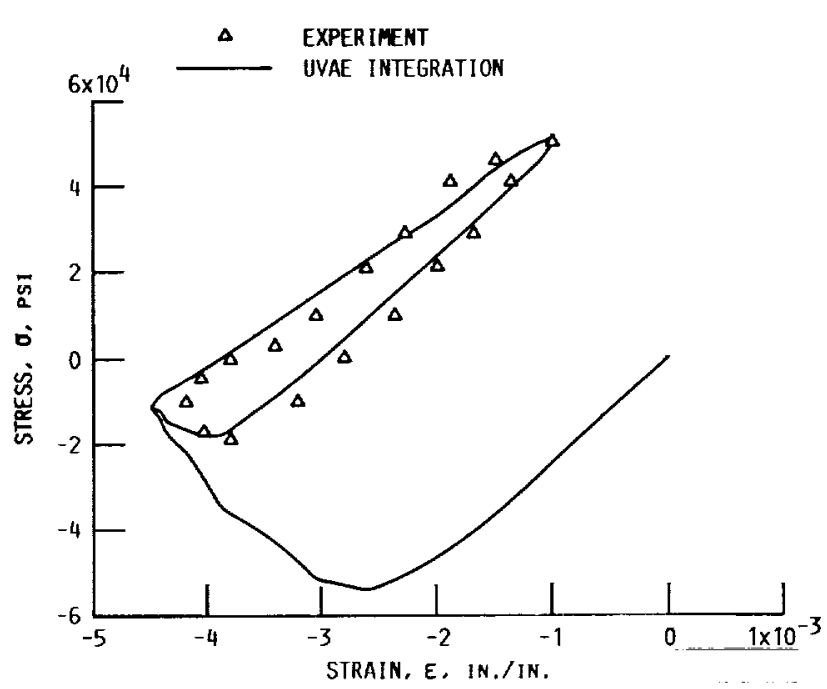

FIG. 12 THERMOMECHANICAL FATIGUE LOOP PREDICTIONS FROM KSR'S INTEGRAL FORM WITH PROPOSED IJVAE INTEGRATION SCHERE. 

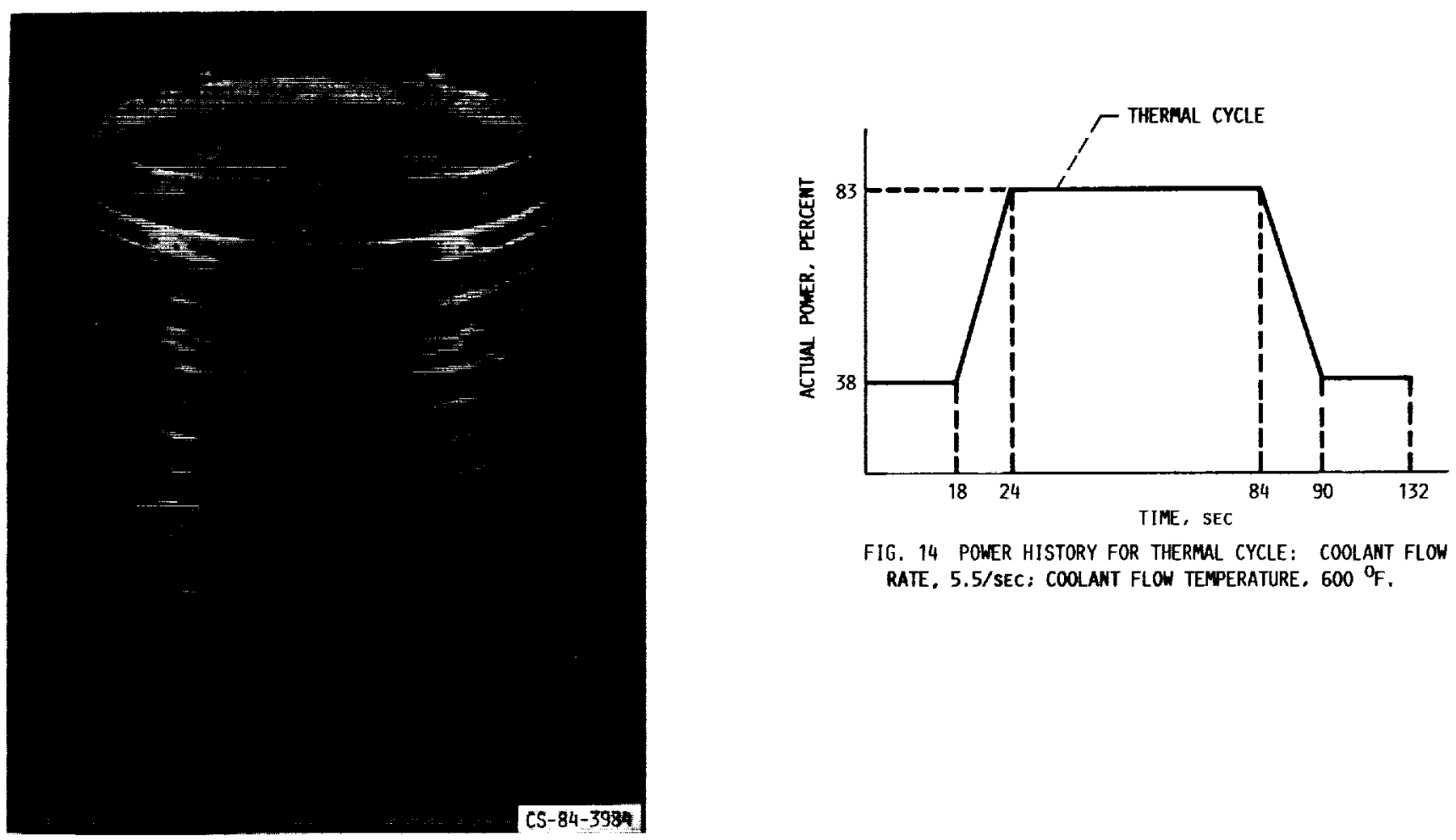

FIG. 14 POWER HISTORY FOR THERMAL CYCLE: COOLANT FLOW RATE, 5.5/SEC: COOLANT FLON TEMPERATURE, $600^{\circ} \mathrm{F}$.

(a) STACKED RING LOUVER IIINER.

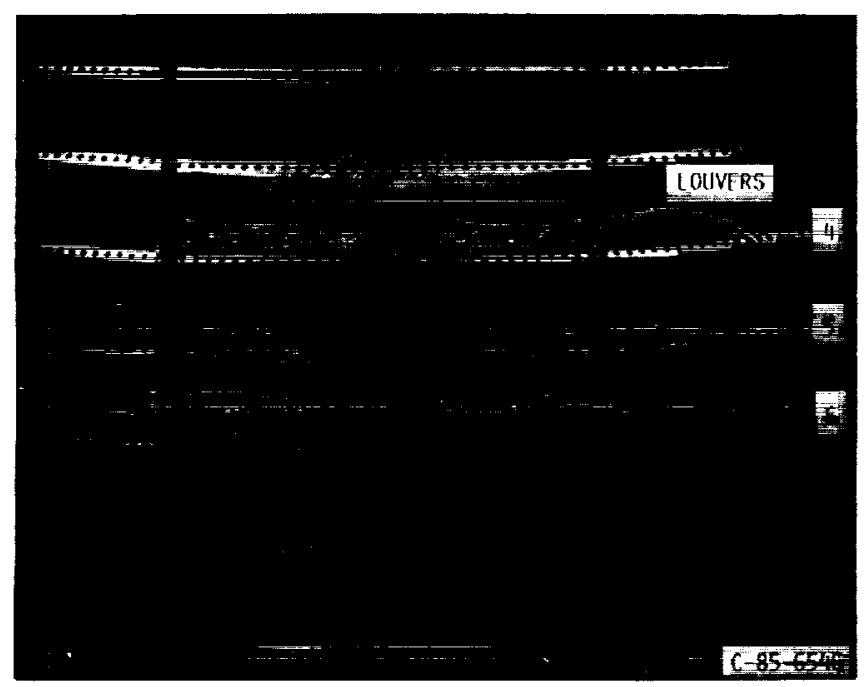

(b) CLOSE-IJP OF LOUVERS 4, 5, AND 6.

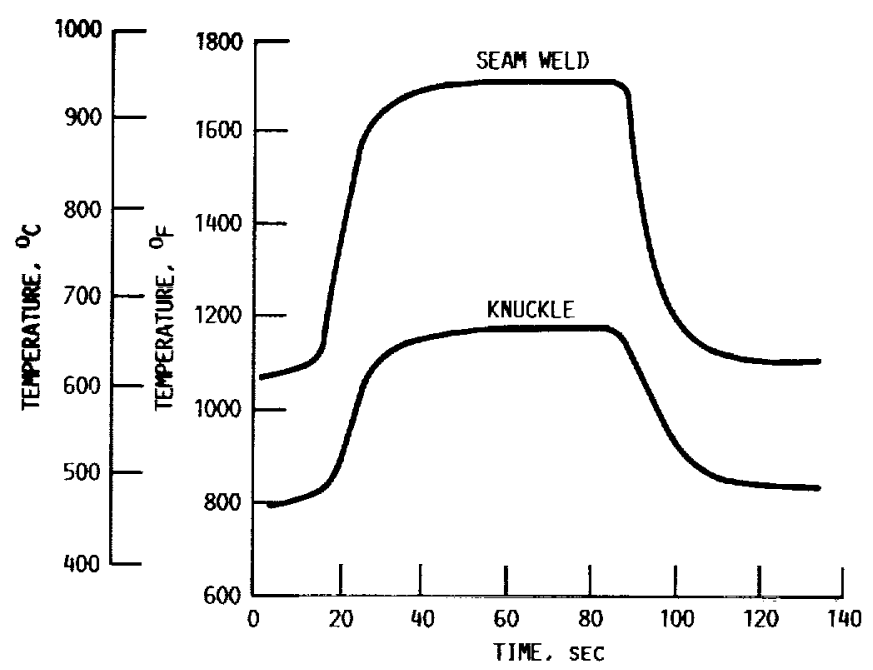

FIG. 15 CYCLIC SURFACE LINER TEMPERATURES AT TWO LOCATIONS ON LOUVER 5.

FIG, 13 AMNULAR COMBUSTOR LINER.

\author{
ORIGINAL PAGE \\ BLACK AND WHITE PHOTOGRAPH
}




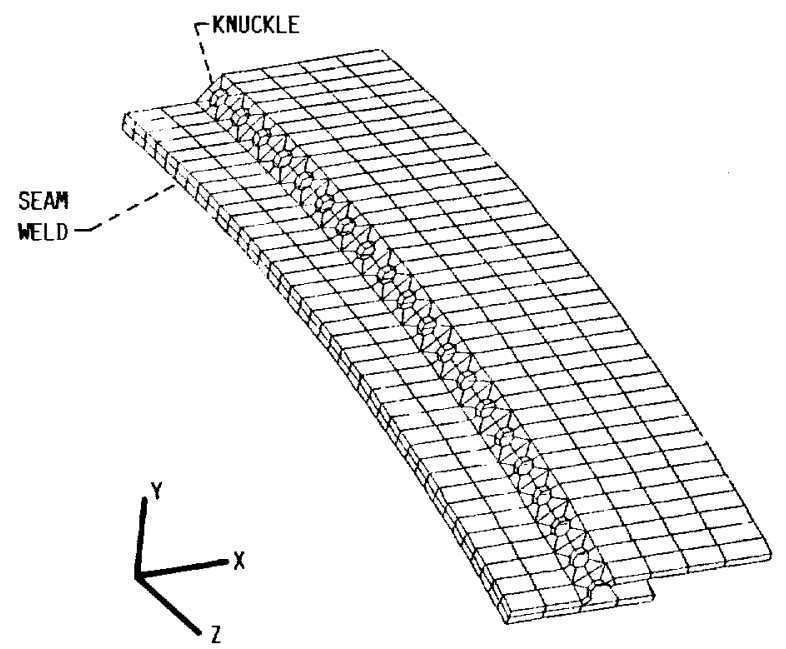

FIG. 16 COMBUSTOR LINER FINITE ELEMENT MODEL: THREEDIMENS IONAL SOL ID ELEMENT WITH 546 ELEMENTS AND 1274 NODES.

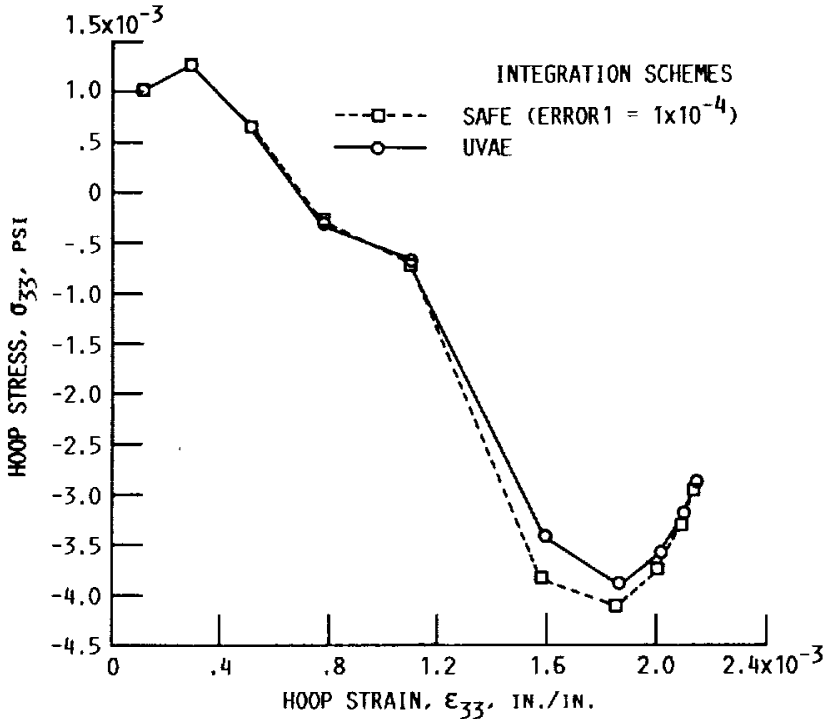

FIG. 17 STRESS-STRAIN PREDICTION AT SEAM WELD (ELENENT 94. INTEGRATION PT. 1).

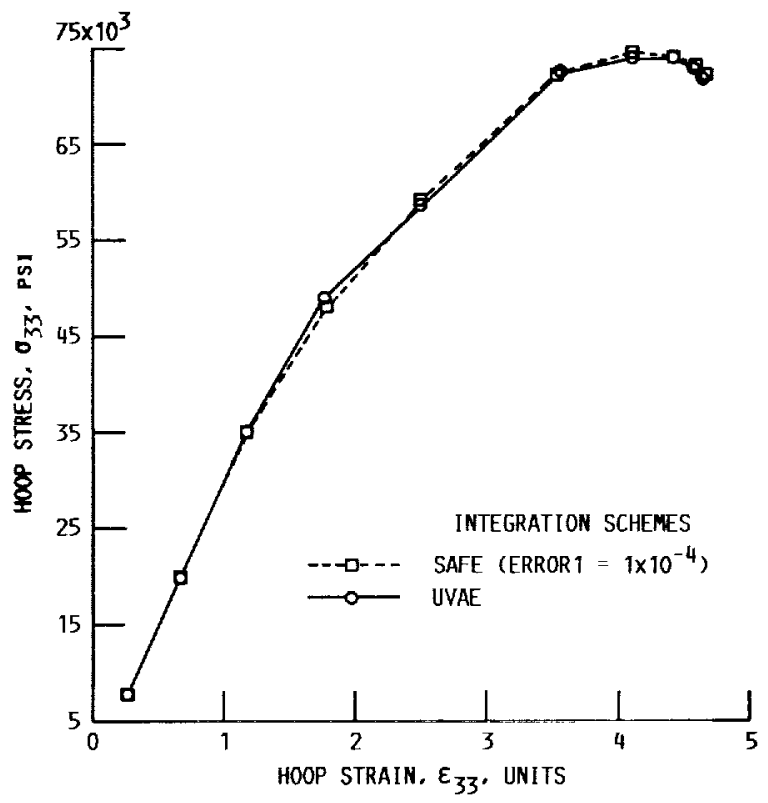

FIG. 18 STRESS-STRAIN PREDICIION AT KNUCKLE (ELEMENT 416. INTEGRATION PT, 1). 


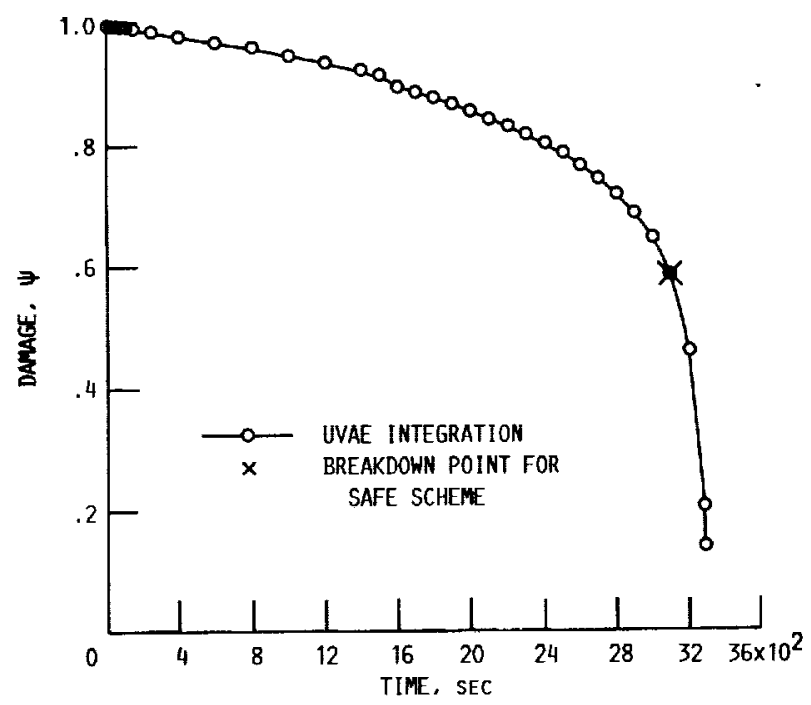

FIG. 19 WALKER'S DAMAGE PARAMETER PREDICTION.

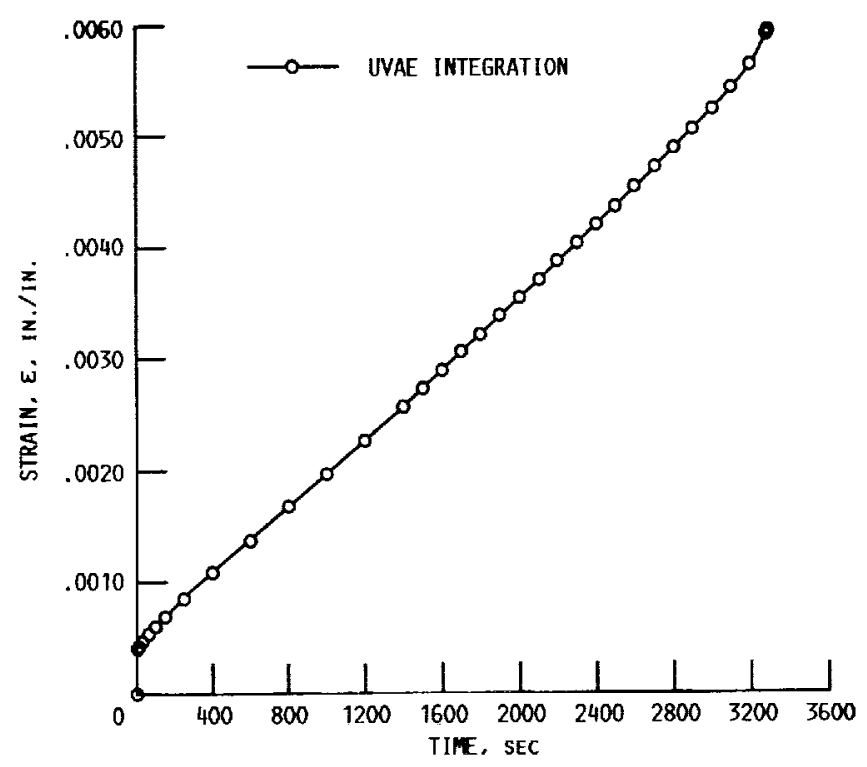

FIG. 20 WALKER'S STRAIN DAMGE PREDICTION. 


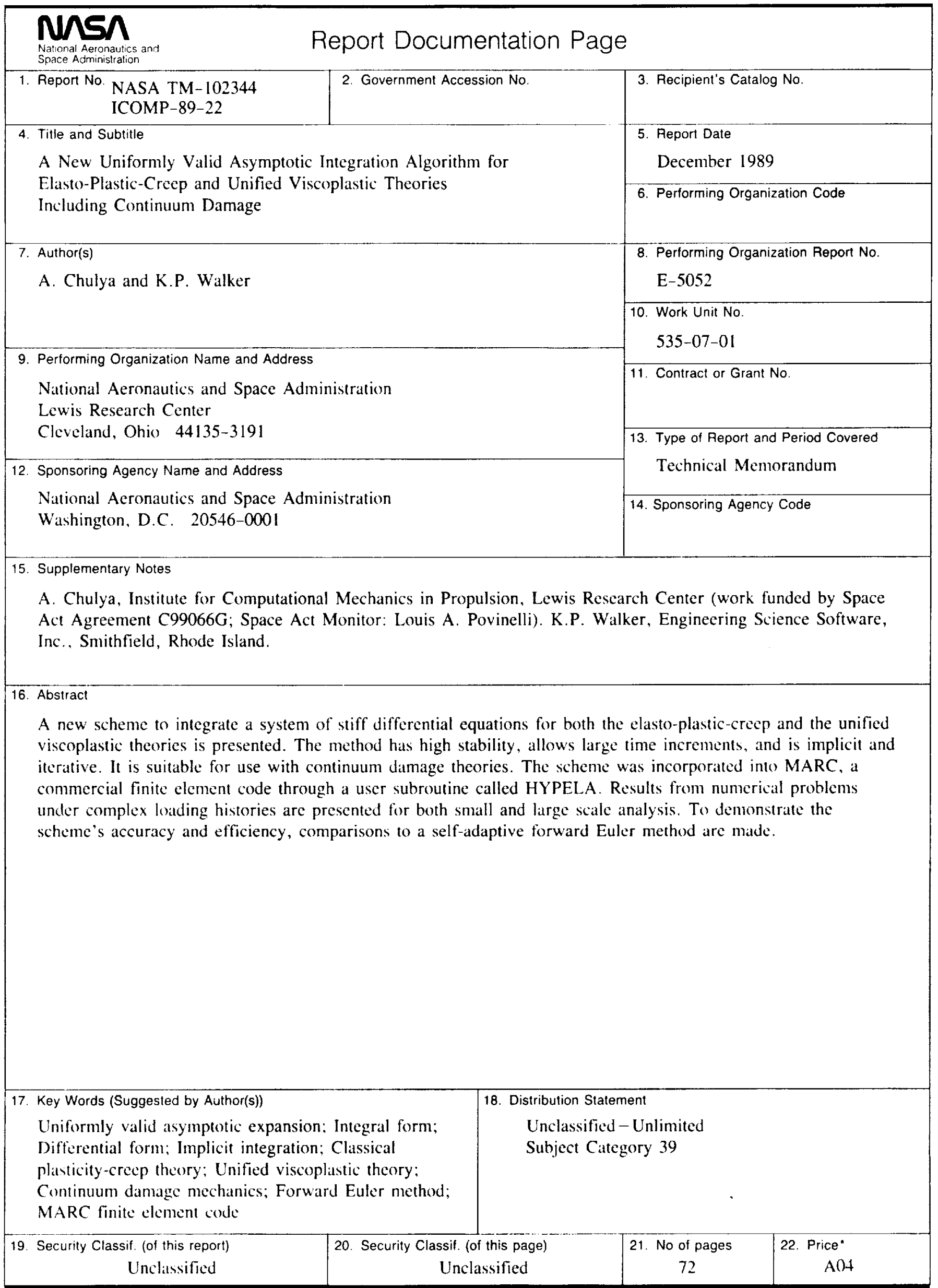


III' $1:$ 